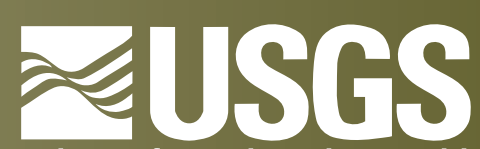

Investigation of the Structure and Lithology of Bedrock Concealed by Basin Fill, Using Ground-Based MagneticField-Profile Data Acquired in the San Rafael Basin, Southeastern Arizona

Scientific Investigations Report 2013-5038 
This page left intentionally blank. 


\section{Investigation of the Structure and Lithology of Bedrock Concealed by Basin Fill, Using Ground-Based Magnetic-Field-Profile Data Acquired in the San Rafael Basin, Southeastern Arizona}

By Mark W. Bultman

Scientific Investigations Report 2013-5038 


\section{U.S. Department of the Interior SALLY JEWELL, Secretary}

\section{U.S. Geological Survey \\ Suzette M. Kimball, Acting Director}

\section{U.S. Geological Survey, Reston, Virginia: 2013}

For product and ordering information: World Wide Web: http://www.usgs.gov/pubprod Telephone: 1-888-ASK-USGS

For more information on the USGS - the Federal source for science about the Earth, its natural and living resources, natural hazards, and the environment:

World Wide Web: http://www.usgs.gov

Telephone: 1-888-ASK-USGS

Any use of trade, firm, or product names is for descriptive purposes only and does not imply endorsement by the U.S. Government.

Although this information product, for the most part, is in the public domain, it also may contain copyrighted materials as noted in the text. Permission to reproduce copyrighted items must be secured from the copyright owner..

Suggested citation:

Bultman, M.W., 2013, Investigation of the structure and lithology of bedrock concealed by basin fill, using groundbased magnetic-field-profile data acquired in the San Rafael Basin, southeastern Arizona: U.S. Geological Survey Scientific Investigations Report 2013-5038, 26 p. 


\section{Contents}

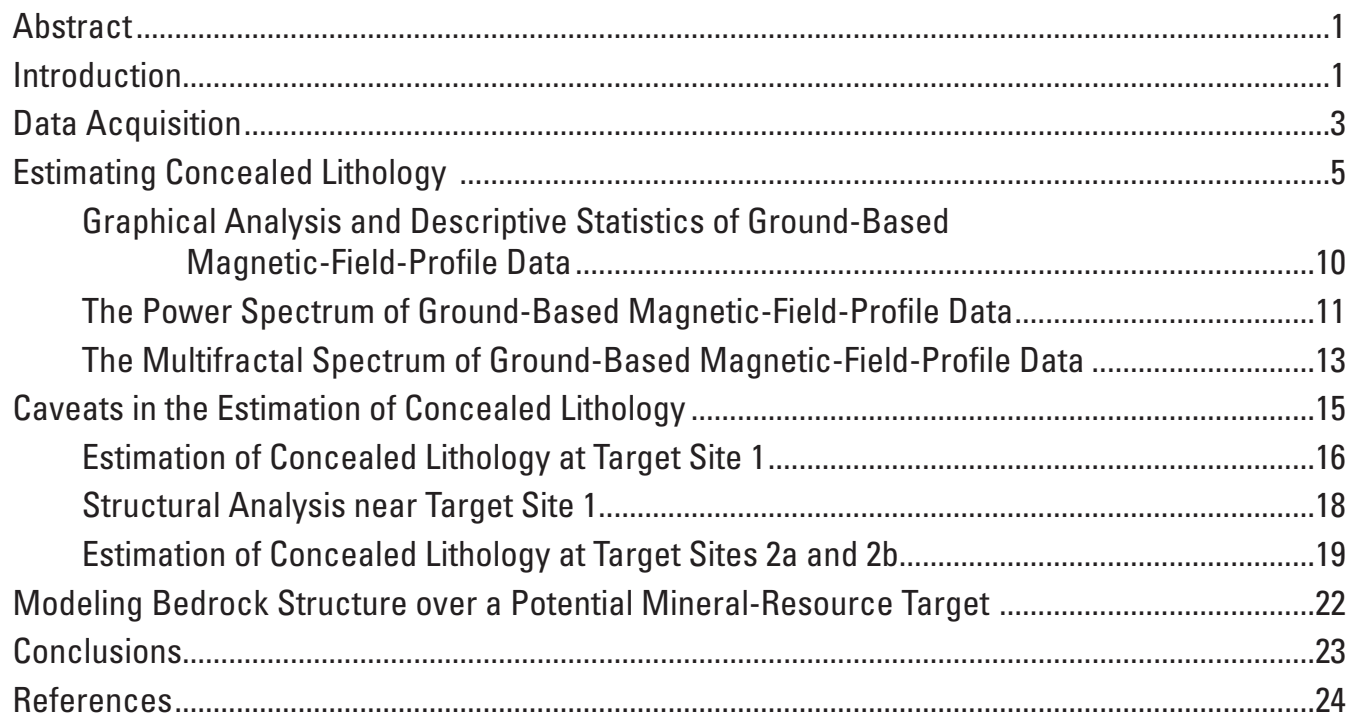

\section{Figures}

1. Illustration showing a cross section of a typical basin in the Basin and Range geologic province....................................................................

2. Photograph of a basin-fill/bedrock contact visible in a small stream valley in the San Rafael Basin...............................................................................................

3. Data showing the Earth's total-intensity magnetic field acquired at 3.5-m height above ground over exposed bedrock .......................................

4. Photograph of a truck-mounted magnetometer acquiring data on the Earth's total-intensity magnetic field in the San Rafael Valley ..............................

5. Plot showing the heading error for truck-mounted magnetometer in the San Rafael Valley ................................................................................................

6. Plot showing truck-mounted magnetometer noise plotted along profile ...................................

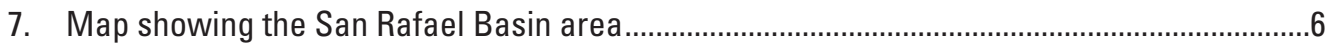

8. Geologic map of the San Rafael Basin area

9. Image showing a Landsat Thematic Mapper (TM) image of the San Rafael Basin, southeastern Arizona in June 1999..........................................7

10. Geologic map of the San Rafael Basin, southeast Arizona with basin depth contours based on a gravity model......................................................

11. Plot showing heading corrected magnetic signatures of candidate lithologies and deep basin fill in the San Rafael Basin ...................................

12. Plot showing decorrugated heading corrected magnetic signatures of candidate lithologies and deep basin fill in the San Rafael Basin .................................10

13. Plot showing power spectra of candidate lithologies and deep basin fill in the San Rafael Basin .................................................................

14. Plot showing power spectrum of map unit TKvs ...............................................................13 
15. Plot showing pultifractal spectra of ground-based magnetic-fieldprofile data acquired over exposed bedrock lithologies

16. Plot showing multifractal spectrum of ground-based magnetic-field-profile data

17. Plot showing ground-based magnetic-field-profile data over the three high-amplitude candidate lithologies.

18. Plot showing power spectra of target site 1 and three high-amplitude candidate lithologies.

19. Plot showing multifractal spectra of ground-based magnetic-field-profile data acquired over candidate lithologies

20. Plot showing ground-based magnetic-field-profile data acquired over basin fill along profile 1.

21. Figures showing profile 1, how ground-based magnetic-field-profile data provide detailed geologic model of concealed lithology and bedrock geometry............19

22. Plot showing ground-based magnetic-filed-profile data from target sites $2 \mathrm{a}$ and $2 \mathrm{~b}$............20

23. Plot showing power spectra for target sites $2 a$ and $2 b$ and three high-amplitude candidate lithologies.......

24. Plot showing multifractal spectra of ground-based magnetic-field-profile data acquired over candidate lithologies

25. Plot showing heading-corrected ground-based magnetic-field-profile data for profile 2 ....22

26. Figures showing profile 2, how ground-based magnetic-field-profile data provide a detailed model of concealed lithology, bedrock geometry, and a mineral resource target.

\section{Tables}

1. Explanation of selected map units

2. Descriptive statistics for candidate lithologies and deep basin fill. 


\title{
Investigation of the Structure and Lithology of Bedrock Concealed by Basin Fill, Using Ground-Based Magnetic- Field-Profile Data Acquired in the San Rafael Basin, Southeastern Arizona
}

\author{
By Mark W. Bultman
}

\section{Abstract}

Data on the Earth's total-intensity magnetic field acquired near ground level and at measurement intervals as small as $1 \mathrm{~m}$ include information on the spatial distribution of nearsurface magnetic dipoles that in many cases are unique to a specific lithology. Such spatial information is expressed in the texture (physical appearance or characteristics) of the data at scales of hundreds of meters to kilometers. These magnetic textures are characterized by several descriptive statistics, their power spectrum, and their multifractal spectrum. On the basis of a graphical comparison and textural characterization, ground-based magnetic-field profile data can be used to estimate bedrock lithology concealed by as much as $100 \mathrm{~m}$ of basin fill in some cases, information that is especially important in assessing and exploring for concealed mineral deposits. I demonstrate that multifractal spectra of ground-based magneticfield-profile data can be used to differentiate exposed lithologies and that the shape and position of the multifractal spectrum of the ground-based magnetic-field-profile of concealed lithologies can be matched to the upward-continued multifractal spectrum of an exposed lithology to help distinguish the concealed lithology.

In addition, ground-based magnetic-field-profile data also detect minute differences in the magnetic susceptibility of rocks over small horizontal and vertical distances and so can be used for precise modeling of bedrock geometry and structure, even when that bedrock is concealed by $100 \mathrm{~m}$ or more of nonmagnetic basin fill. Such data contain valuable geologic information on the bedrock concealed by basin fill that may not be so visible in aeromagnetic data, including areas of hydrothermal alteration, faults, and other bedrock structures. Interpretation of these data in the San Rafael Basin, southeastern Arizona, has yielded results for estimating concealed lithologies, concealed structural geology, and a concealed potential mineral-resource target.

\section{Introduction}

The Basin and Range geologic province of North America supplies nearly all the copper and most of the gold and silver mined in the United States. Most producing mineral deposits in this region occur in exposed bedrock that occupies only about 38 percent of land cover (Heathcote, 1983). An accurate understanding of the remaining potential for undiscovered mineral deposits in the Basin and Range (and in many other areas) requires knowledge of the structure and lithology of the bedrock that is concealed by relatively shallow basin fill, primarily on the piedmont slopes of the ranges (fig. 1), an area also referred to as the basin margin (fig. 2).
Figure 1. Illustration showing a cross section of a typical basin in the Basin and Range geologic province (after Pierce, 1985).

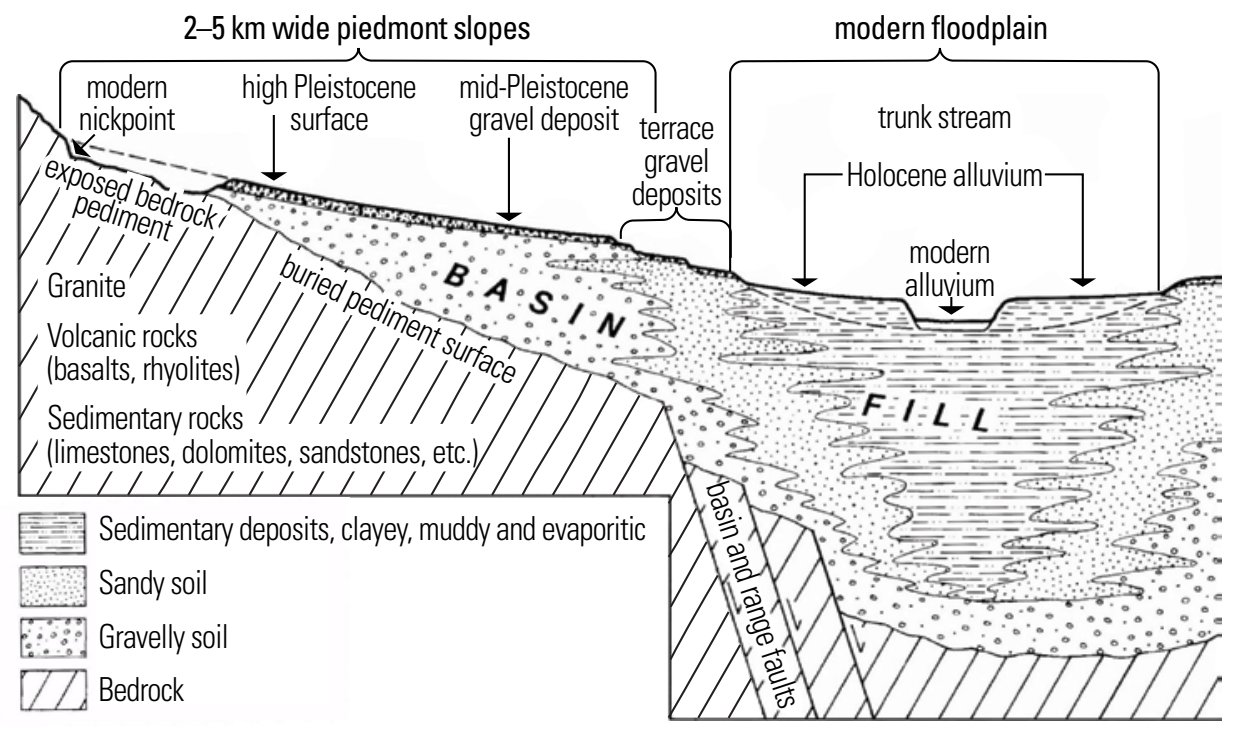


Identification of concealed lithology at regional scales by using aeromagnetic data has been shown to be feasible by Gettings (2008). This study focuses on the identification of concealed lithology and the structural interpretation of magnetic-field-profile data at larger scales (hundreds of meters to kilometers) for use in the study of basin margins. At these scales, aeromagnetic data generally contain insufficient information for the estimation of concealed lithology or precise structural modeling of concealed bedrock. Information on the Earth's totalintensity magnetic field is lost extremely fast as the magnetic sensor moves away from the ground, and so for large-scale interpretations magnetic-field data must be acquired as near to the ground and as closely spaced as possible.

Profiles created from near-ground, closely spaced total-intensity-magneticfield data are generally much rougher in appearance than those created from aeromagnetic data, even those acquired at low altitude, owing to the greater information content of near-ground data relative to aeromagnetic data, commonly acquired at altitudes of 100 to $300 \mathrm{~m}$ above the surface. Such near-ground data, which are acquired by using a magnetometer mounted on a utility vehicle, are herein referred to as "ground-based magnetic-field-profile data" and the acquired data as the "magnetic signal," which may be from a specific exposed lithology (map unit) or from a target site over basin fill where the identity of the lithology concealed by the basin fill is to be determined. Acquisition of data near the ground (near the magnetic sources) maximizes the information content extracted from the Earth's total-intensity magnetic field, information important in discriminating the magnetic signal from both exposed and concealed lithologies. The high information content of ground-based magnetic-field-profile data also allows for the use of novel techniques in data analysis.

A typical ground-based magnetic-field-profile is shown in figure 3. Upward continuation of the data illustrates how the data would appear if acquired at a height above ground equal to the value of upward continuation. High-precision aeromagnetic data are commonly acquired at an altitude of $100 \mathrm{~m}$ in lowrelief areas and at altitudes of $300 \mathrm{~m}$ or more in mountainous areas. Most compilations of aeromagnetic data use the highest survey as a common denominator so that any surveys flown at lower altitudes are upward continued to the height of the highest survey, commonly $300 \mathrm{~m}$ or more. The large-scale features visible in ground-based magnetic-field-profile data are lost in airborne data (fig. 3).

The rough appearance of ground-based magnetic-fieldprofile data reflects the heterogeneous distribution of magnetic sources and their susceptibilities within the volume of rock

contributing to the signal acquired by the sensor. Because this distribution of magnetic sources is often unique to individual lithologies, ground-based magnetic-field-profile data acquired over an exposed lithology generally represent the magnetic signature of that lithology, at least locally. These data can be plotted and compared by using their textural properties (physical appearance or characteristics). In addition, nearground magnetic-field-profile data can contain precise information on contacts and fault locations and the depth of burial of concealed magnetic bedrock.

When a lithology with a distinctive and high-amplitude magnetic signature is concealed by nonmagnetic basin fill, in some cases the textural properties of that lithology's magnetic signature can be observed and identified through the basin fill if the depth of burial is known and not too deep (generally less than $100 \mathrm{~m}$ ), if the magnetic signature of the concealed lithology has a high amplitude so that its properties are identifiable at depth, and if the magnetic properties of the basin fill are negligible.

Some concealed lithologies can be estimated by matching the magnetic signature of the ground-based magnetic-fieldprofile data acquired over shallow basin fill with that of similar data acquired over nearby exposed bedrock, called candidate lithologies. To match these signatures, the data acquired over candidate lithologies are upward continued to the estimated depth of burial (generally based on a gravity survey or other information) of the concealed bedrock. Magnetic data representing just the basin fill (from a deep part of the basin) are added to the upward-continued candidate lithology's data if needed. Graphical analysis, statistical analysis, and spectral 
and multifractal properties of the ground-based magnetic-fieldprofile data are then used to compare the upward-continued magnetic signatures of the candidate lithologies with the magnetic signal from the concealed bedrock lithology. Although a perfectly quantitative match generally does not occur, both graphical analysis and the statistical, spectral, and multifractal properties of the data each provide information that may allow for the elimination of one or more candidate lithologies or even uniquely define a concealed lithology. Even when this identification is not obtained, the data, in combination with knowledge of the local geology, can at least allow estimation of a concealed lithology.

Large-scale structural interpretation of near-ground magnetic-field-profile data yields much information that is not discernible in aeromagnetic data. Even when flown at an altitude of $100 \mathrm{~m}$, aeromagnetic data lose the ability to discern steep gradients on anomalies, information that is important to the understanding of structure in basin bedrock. Because of the closely spaced acquisition locations of near-ground magneticfield-profile data and the high information content of these data near ground, ground-based magnetic-field-profile data contain information that allows estimation of the geometry and structure of shallow bedrock with a high degree of precision.

\section{Data Acquisition}

The ground-based magnetic-field-profile data used here were acquired with a Geometrics G-823A Cs-vapor magnetometer mounted approximately $3.5 \mathrm{~m}$ above the Earth's surface and $4 \mathrm{~m}$ directly behind a four-wheel-drive utility vehicle on July 20, 2008. A tripod arrangement of fiberglass windsurfer masts were used to suspend the magnetometer sensor (fig. 4) off the back of the utility vehicle. All mounting hardware was built from fiberglass, polyvinyl chloride, aluminum, bronze, or brass. Data were acquired at $10 \mathrm{~Hz}$ and logged to a computer. The magnetometer was accurate to better than $2 \mathrm{nT}$ throughout the range of orientations where a signal was strong enough to be acquired. Over most common angular orientations of the sensor, the sensor was compensated to be accurate within less than $0.5 \mathrm{nT}$ (Geometrics, 1996).

Steel in the utility vehicle contributed to a large anomaly from the induced magnetic field due to the vehicle itself. The mounting system was designed to move the sensor as far away from the vehicle anomaly as practical and to minimize sensor movement with respect to the vehicle. Also, several neodymium magnets were placed along the rear of the vehicle in an attempt to counter the vehicle's magnetic field. Even

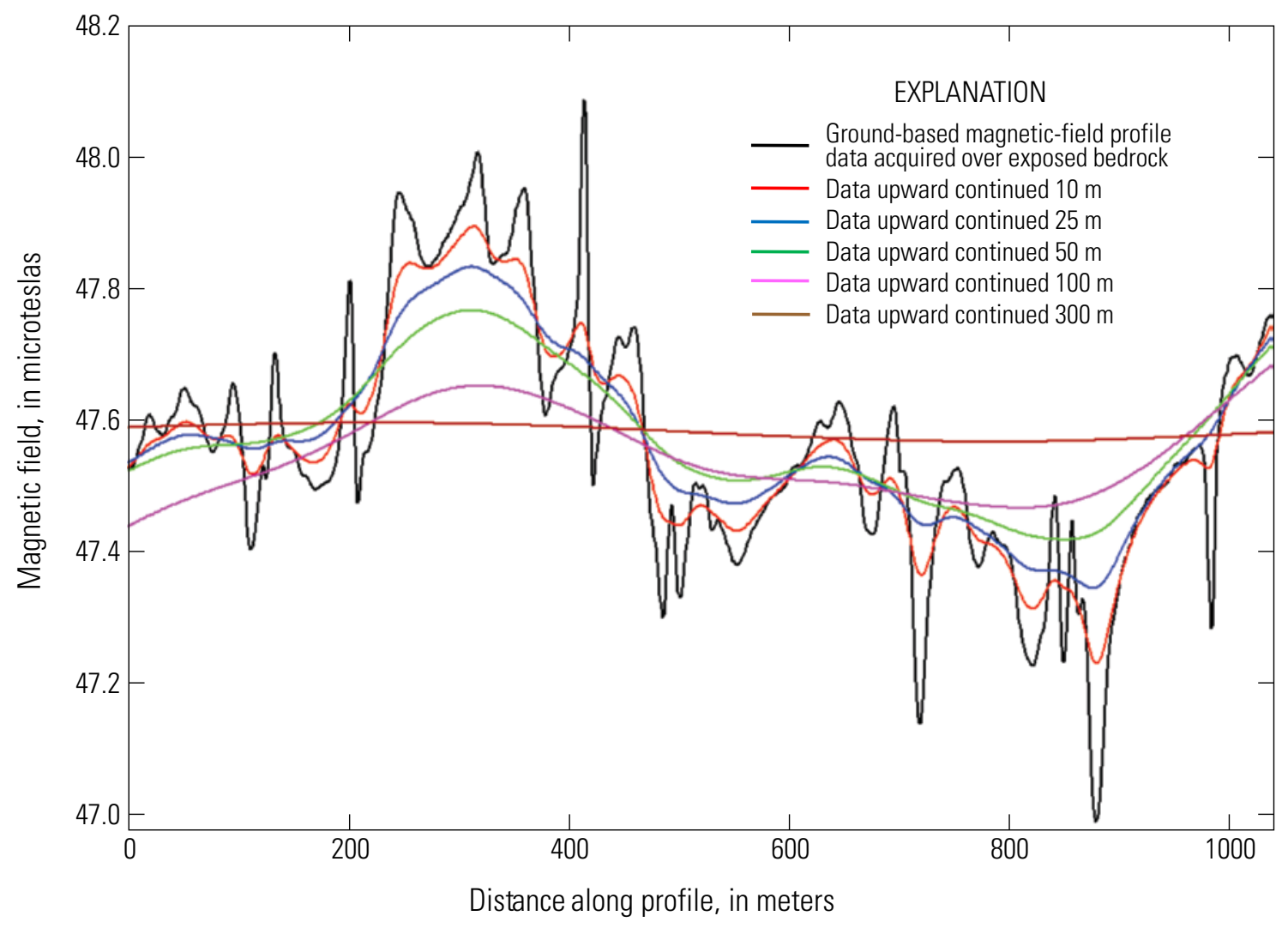

Figure 3. Data showing the Earth's total-intensity magnetic field acquired at 3.5- $\mathrm{m}$ height above ground over exposed bedrock and upward continued by 10,25,50, 100 and $300 \mathrm{~m}$ to show how the data would look if acquired from the air. A height of $300 \mathrm{~m}$ above ground is common for aeromagnetic surveys. 
with these modifications, however, the interaction of the vehicle's magnetic anomaly with the inclined Earth's magnetic field introduced a large heading correction to the system. This heading correction was unique to each region being surveyed, as shown in figure 5 . The heading correction was treated in only two dimensions since no pitch or roll measurements for the vehicle were available. Because the data were analyzed along relatively short continuous profiles, International Geomagnetic Reference Field (IGRF) and diurnal corrections were not usually needed. If data are acquired in a region at differing time periods, a correction can be applied on the basis of leveling. Data were also analyzed as true values, not as anomaly values, because the mean values of the Earth's total magnetic field over a given lithology are related to that lithology's magnetic susceptibility and the use of magneticanomaly values removes that information.

Location information was obtained with a Wide-Area Augmentation System (WAAS)-enabled Global Positioning System (GPS) instrument, generally with an accuracy of $4 \mathrm{~m}$ or better. GPS information was logged to the computer at $1 \mathrm{~Hz}$ and used to calculate vehicle heading. The location of the each magnetic signal's data point, recorded at $10 \mathrm{~Hz}$, was interpolated from the 1-Hz GPS data. In addition, the utility-vehicle platform is capable of acquiring data with a GR-320 gamma-ray spectrometer equipped with a 4-L NaI detector crystal (fig. 4).

Data for the heading correction were based entirely on GPS readings. Because this signal can have a short-term variance on the order of meters, in a few areas of poor GPS reception the interpolated heading data were smoothed through a running-mean filter 21 data points long (two GPS readings). Owing to the large heading correction for the vehicle (fig. 5), straight roads were preferred where possible, and north-south

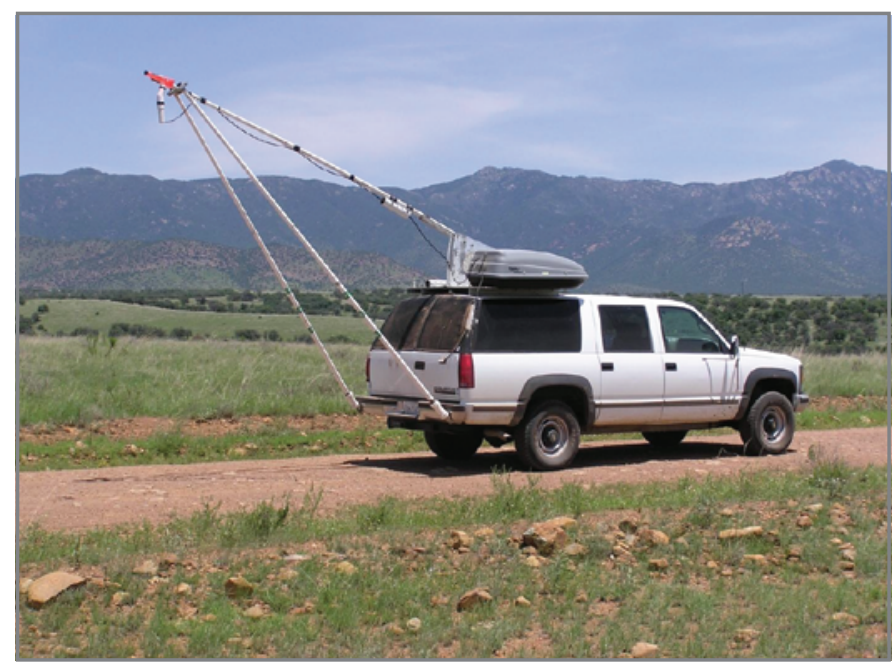

Figure 4. Photograph of a truck-mounted magnetometer acquiring data on the Earth's total-intensity magnetic field in the San Rafael Valley, southeastern Arizona (see figs., 7 and 8). Roof mounted cargo container holds a $4 \mathrm{~L} \mathrm{NI}$ crystal that is used with a GR-320 gamma ray spectrometer. routes were preferred, owing to the smaller change in heading correction as a function of direction along these roads. Also, data from sharp corners (for example, a $90^{\circ}$ corner with a small radius of curvature) generally were not used because GPS data may not accurately reflect the position of the vehicle with respect to the Earth's magnetic field over short timespans, owing to the 1-s acquisition rate of the GPS instrument, which may be even longer in areas of heavy vegetation. All GPS data were inspected to ensure that an anomaly at a corner was not due to a heading correction. All the data used in this analysis have been heading corrected.

The noise created from movement of the sensor with respect to the magnetic anomaly of the vehicle was measured by driving the vehicle over a typical unpaved surface in an area of a relatively flat magnetic field, here the deep part of the basin where the observed amplitudes of magnetic anomalies due to geologic features are no larger than $30 \mathrm{nT}$ (fig. 6). This noise estimated from sensor movement is the $\pm \sim 4-\mathrm{nT}$ component of the signal visible in figure 6 , and no appreciable noise difference was observed in the magnetic signal acquired while driving at different speeds. Given that most anomalies of interest in groundbased magnetic-field-profile data are hundreds to thousands of nanoteslas, this noise is unimportant to the analysis. By comparing data acquired over deep basin fill on hills of varying aspect and slope, three-dimensional heading corrections due to pitch and roll were determined to be negligible.

Large, narrow excursions in the magnetic field (commonly with amplitudes of thousands of nanoteslas) were generally from cultural features, such as bridges and culverts. Cultural features were determined by matching the locations of their large associated magnetic anomalies with features determined from aerial photography. The availability

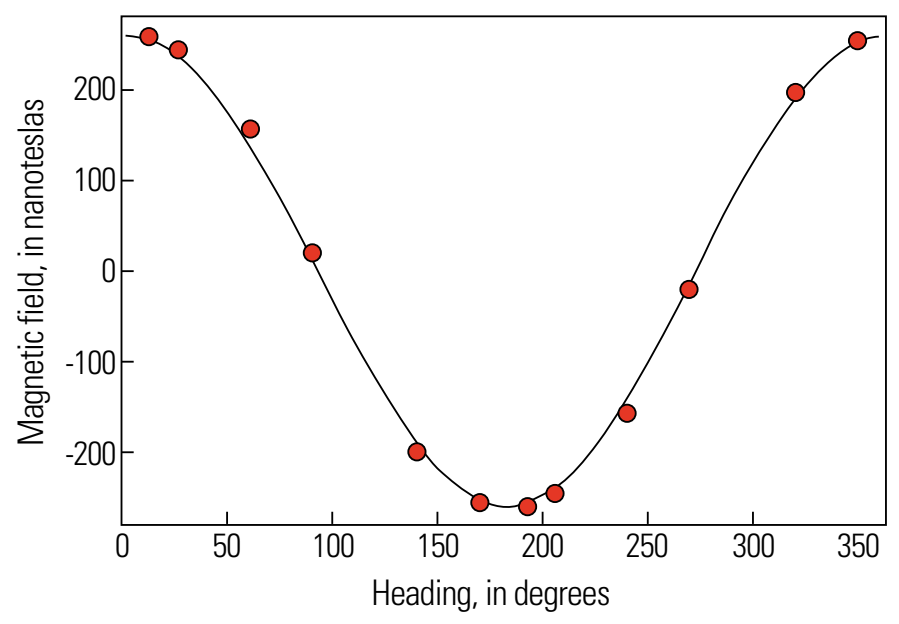

Figure 5. Plot showing the heading error for truck-mounted magnetometer in the San Rafael Valley, southeastern Arizona. Red circles, data obtained at $180^{\circ}$ offsets in heading, all in a small region with a flat magnetic filed. Curve is a sine wave with an amplitude of $260 \mathrm{nT}$, centered on an azimuth of $003^{\circ}$, declination at this site is $10.4^{\circ}$ 
of aerial-photographic data from online mapping services greatly facilitated both acquisition and interpretation of the ground-based magnetic-field-profile data. These anomalies were removed by hand for quantitative analysis of the signal or simply identified if the profile was analyzed qualitatively.

The fast Fourier transform-based spectral interpretation and multifractal analyses used in this study both required equally spaced intervals in the data. Therefore, in these analyses only, the raw data were resampled at a 1-m interval, allowing the wavenumber plots used in spectral interpretation to have properties that are easily interpreted; that is, the wavenumber units are inverse meters. Whenever this resampling was done, the resampled data were compared to the original data to ensure that the resampled data correctly represented the original data.

\section{Estimating Concealed Lithology}

The San Rafael Basin, southeastern Arizona (figs. 7, 8), was chosen as a study area to demonstrate the benefits of ground-based magnetic-field-profile data. The study area lies in the porphyry copper and large-deposit mining district of southeastern Arizona (Bultman and Drewes, 1996). In addition, the San Rafael Basin is bounded by major northwesttrending fault systems that may control the emplacement of intrusive bodies responsible for the generation of porphyry copper and other ore deposits (Hildenbrand, 2000). Several major mineral deposits, including the Red Mountain porphyry copper deposit, the Sunnyside Porphyry copper deposit, and many other deposits, prospects, and occurrences, mostly on the east flanks of the Patagonia Mountains, occur in this region (fig 8; Bultman and Drewes, 1996). Mapped bedrock surrounding the basin includes intrusive and volcanic rocks and a wide variety of potential host rocks, including volcanic sedimentary rocks and Paleozoic limestone and dolomite. In addition, interpretations of previous ground-based magneticfield-profile data (Bultman and Gettings, 1994; Bultman, 1999) indicated that the San Rafael Basin is a geologically complex and prospective area. Bultman presented a model of depth to bedrock in the basin based on gravity data obtained from only a few gravity stations. Nonetheless, his report indicates that the San Rafael Basin has shallow buried pediments along its west and north side. In addition, the basin has a good unpaved-road system that allows vehicle access to many important localities, including the buried pediment on the north and west sides of the basin. The overall depth of the central part of the basin, nearly $1 \mathrm{~km}$, is considered to be well constrained and is controlled by three deep petroleumexploration wells (Bultman, 1999).

Basin fill in the San Rafael Basin is not nonmagnetic. Ground-based magnetic-field-profile data acquired over deep parts of the basin generally display low-amplitude magnetic anomalies of $\pm 10-30 \mathrm{nT}$ (fig. 6). On the basin margins, where the basin is shallow, the anomalies can be larger, whether from basin fill or underlying concealed bedrock. If a lithology with a large-amplitude magnetic signal is concealed below the basin fill, this amplitude may show through the basin fill, provided the concealed lithology is not too deeply buried and the signal from the basin fill does not overwhelm that from the concealed lithology. Concealed lithologies with smallamplitude magnetic signals are undetectable through basin fill and can be eliminated as candidate lithologies when a large amplitude signal is observed in ground-based magnetic-fieldprofile data acquired over shallow basin fill.

Estimation of concealed lithology began by acquiring ground-based magnetic-field-profile data over basin fill and adjacent exposed bedrock in the study area (fig. 7). Data acquired over exposed bedrock were used to identify the textural properties of the magnetic signal of lithologies that may be concealed by basin fill, that is, candidate lithologies.
Figure 6. Plot showing truckmounted magnetometer noise plotted along profile. At least part of high frequency $\pm \sim 4-n T$ noise (total magnetic anomaly height, $\sim 8 \mathrm{nT}$ ) is due to sensor movement with respect to files of utility vehicle. Data were acquired on a typical gravel road over deep basin fill, $\sim 20$ - to $\sim 30-\mathrm{nT}$ anomalies are due to near surface geology.

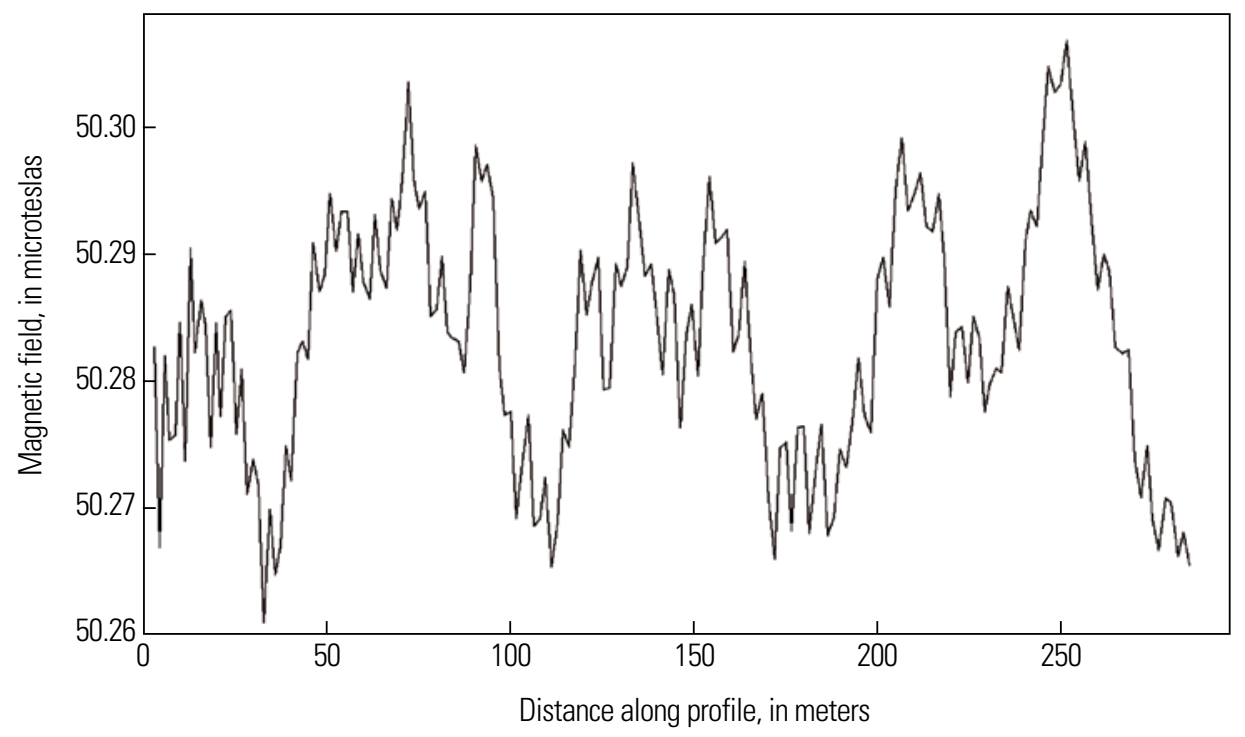


When a candidate lithology has a uniquely describable magnetic signal, the signal is referred to as that lithology's magnetic signature. Data acquired over shallow basin fill were used in an attempt to identify the bedrock lithology concealed by the basin fill at a target site; data acquired over deep basin fill were used to estimate the magnetic signal from the basin fill itself. Whenever possible, the magnetic properties of different facies of exposed basin-fill material were considered, using Landsat Thematic Mapper (TM) imagery.

A June 1999 Landsat TM image of the San Rafael Basin is shown in figure 9. This ratio image, which works well to differentiate lithology, is used here to show how the mineralogy of the surface of the basin fill differs from one part of the basin to another. This type of image is used to locate a possible difference in the magnetic signal from surficial basin fill. In the San Rafael Basin, the northeastern margin of the basin has a relatively high content of Fe oxides and clays, whereas the central part of the surficial basin fill is dominated by nonmagnetic high-silica minerals. The target sites where concealed lithology were inferred (sites 1, 2a, 2b, fig. 9) were chosen partly on the basis of the absence of Fe-rich minerals at the surface as determined from figure 9, but ultimately depend on the locations of the roads used to acquire the data. Site 1 is along a wash (orange-red area, fig. 9) and may have a high Fe oxide mineral content; site 2a (green area, fig. 9) likely contains nonmagnetic siliceous surficial material; and site $2 \mathrm{~b}$ (light-yellow-orange area, fig. 9) may include some Fe oxide minerals that affect the magnetic signal acquired there. The site chosen to represent the basin fill ("QTg-Qg deep basin," fig. 9; and henceforth referred to as "QTg deep basin") lies in silica-rich surface material. From figure 9 it is evident that the mineralogy and, thus, the magnetic signature of basin fill material, on the basis of surface evidence, varies at each target site. Though used only qualitatively, this information helps avoid locating target sites in areas where highly magnetic basin fill may be present at the surface.

Five candidate lithologies were chosen for this study, all of which are exposed at the surface adjacent to the
Figure 7. Map showing the San Rafael Basin area, southeastern Arizona. Red shading denotes the area of figure 8 .

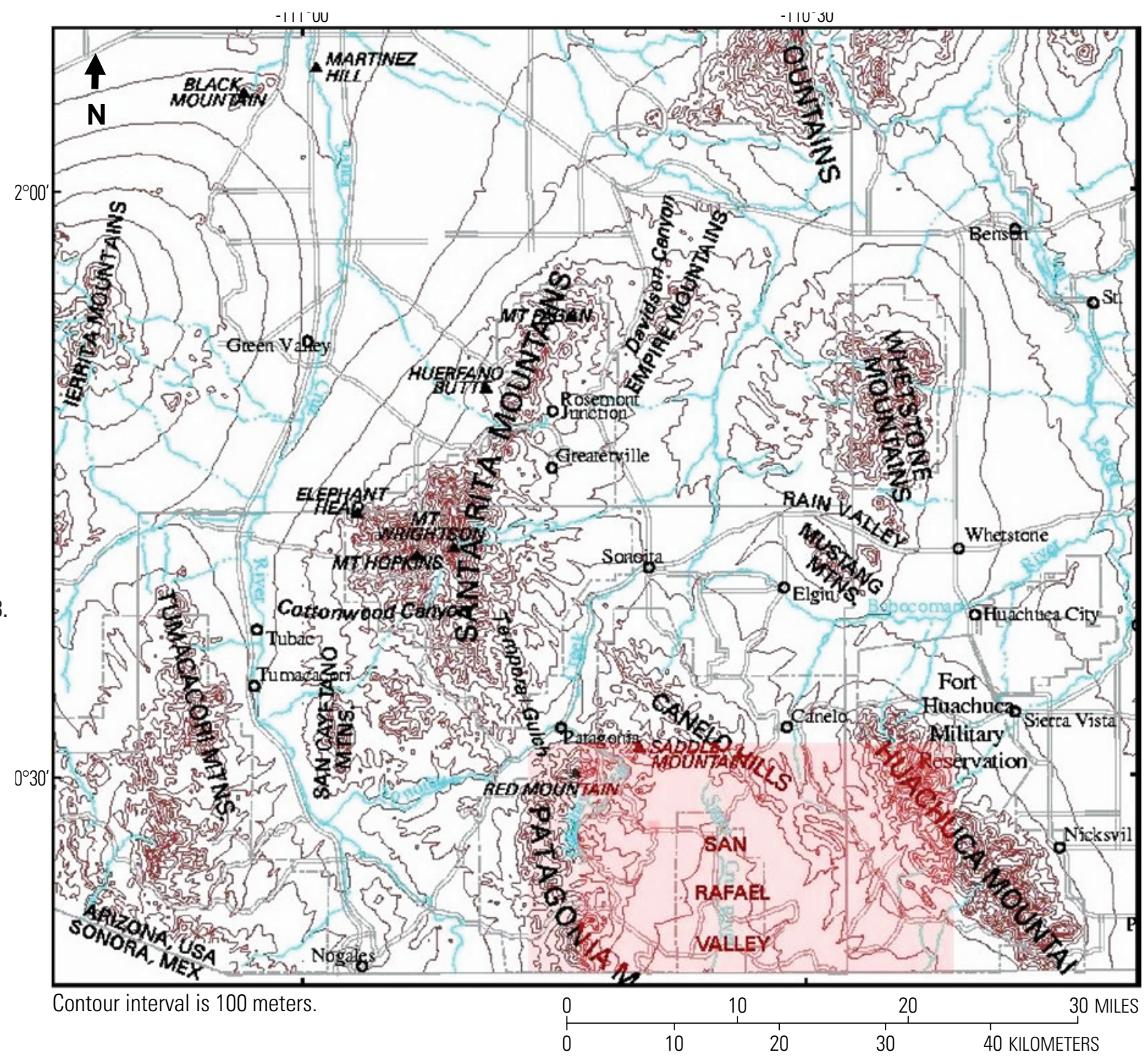


Figure 8. Geologic map of the San Rafael Basin area, southeastern Arizona. $\mathrm{OTg}$ to $\mathrm{Og}$, basin fill. Diamonds, metallic mineral deposits, prospects, and occurrences. Indicated by red numbers are important known porphyry copper deposits: 1) Red Mountain porphyry copper deposit, 2) Sunnyside porphyry copper deposit. Minerals data from the U.S.

Geological Survey (2009), geology from Drewes and others (2002). Descriptions of important map units are listed in table 1.

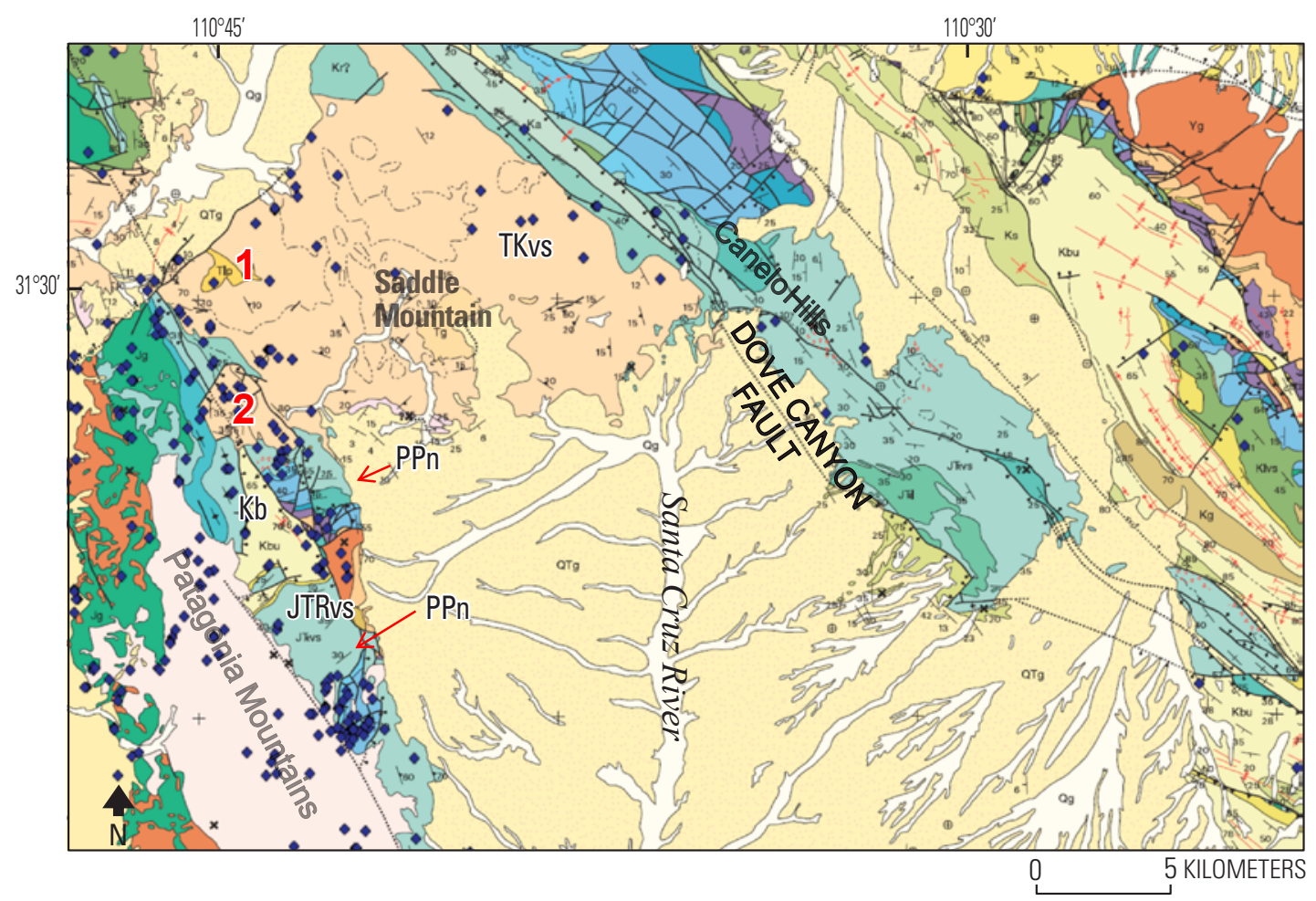

Figure 9. Image showing a Landsat Thematic Mapper (TM) image of the San Rafael Basin, southeastern Arizona in June 1999. TM bands $3 / 1$ in red, TM bands $5 / 4$ in green, and TM bands 5/7 in blue. Reds highlight iron oxides, greens highlight silica, and blues highlight clay minerals. Geologic linework, (thin black lines) from Drewes and others (2002). Site labeled "Otg-0g deep basin" was used to estimate the magnetic properties of basin fill.

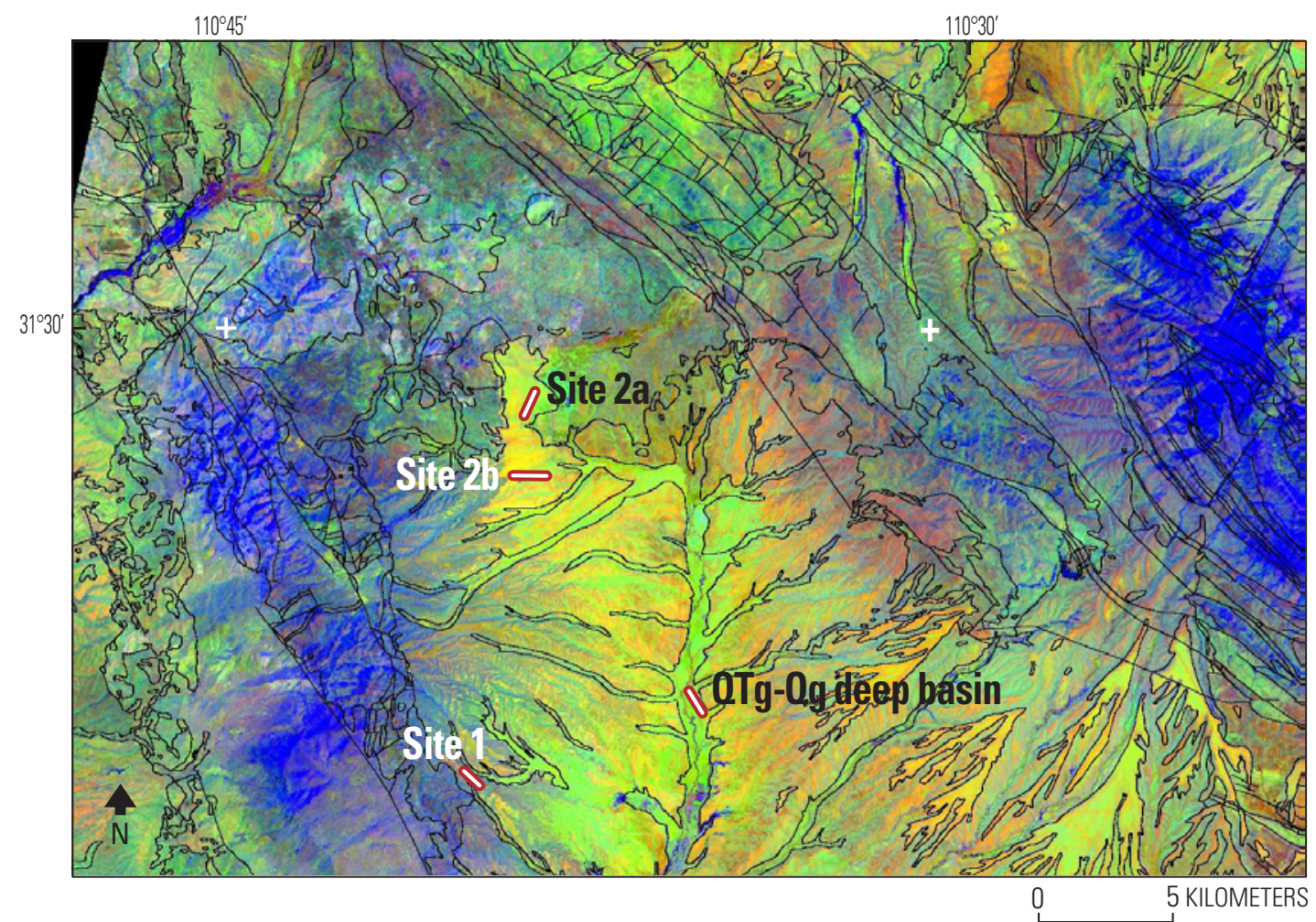


basin and may represent the lithologies concealed by basin fill. The locations chosen for the acquisition of ground-based magnetic-field-profile data to represent these candidate lithologies are shown in figure 10. The candidate lithologies include map units that may be related to porphyry copper or other types of mineralization in the study area including Late Cretaceous through Eocene intrusive rock (map unit TKg, fig. 8; table 1) in the Patagonia Mountains, Late Cretaceous through Eocene volcanic and sedimentary rocks (map unit TKvs) to the north of the basin, and Late Triassic and Jurassic volcanic and sedimentary rocks (map unit JRvs) both east and west of the basin. Two map units (Kbu, PPn) that might serve as mineral-deposit host rocks occur in the eastern Patagonia Mountains. The magnetic signature from the central part of the basin (map unit QTg) is considered in the analysis of data from unknown sites overlying shallow basin fill.

Candidate-lithology map unit TKg (fig. 8, table 1) occurs west of the basin. Although these intrusive rocks have numerous phases, including some with reversed remanent magnetism (Hagstrum, 1994), a nearly $1-\mathrm{km}$ section in the central part appears to be uniform in texture and apparently contains no reversals (fig. 11). Candidatelithology map unit TKvs, which occurs north of the basin and extends westward as far as Red Mountain (fig. 8), also is fairly uniform in texture (fig. 11) over the length of the acquired signal that was used for the magnetic signature. Candidate-lithology map unit Kbu is generally weakly magnetic and is insignificant as a host rock for replacement deposits the study area. Candidatelithology map unit JTRvs (fig. 11 ), which is primarily andesitic in the area directly east of map

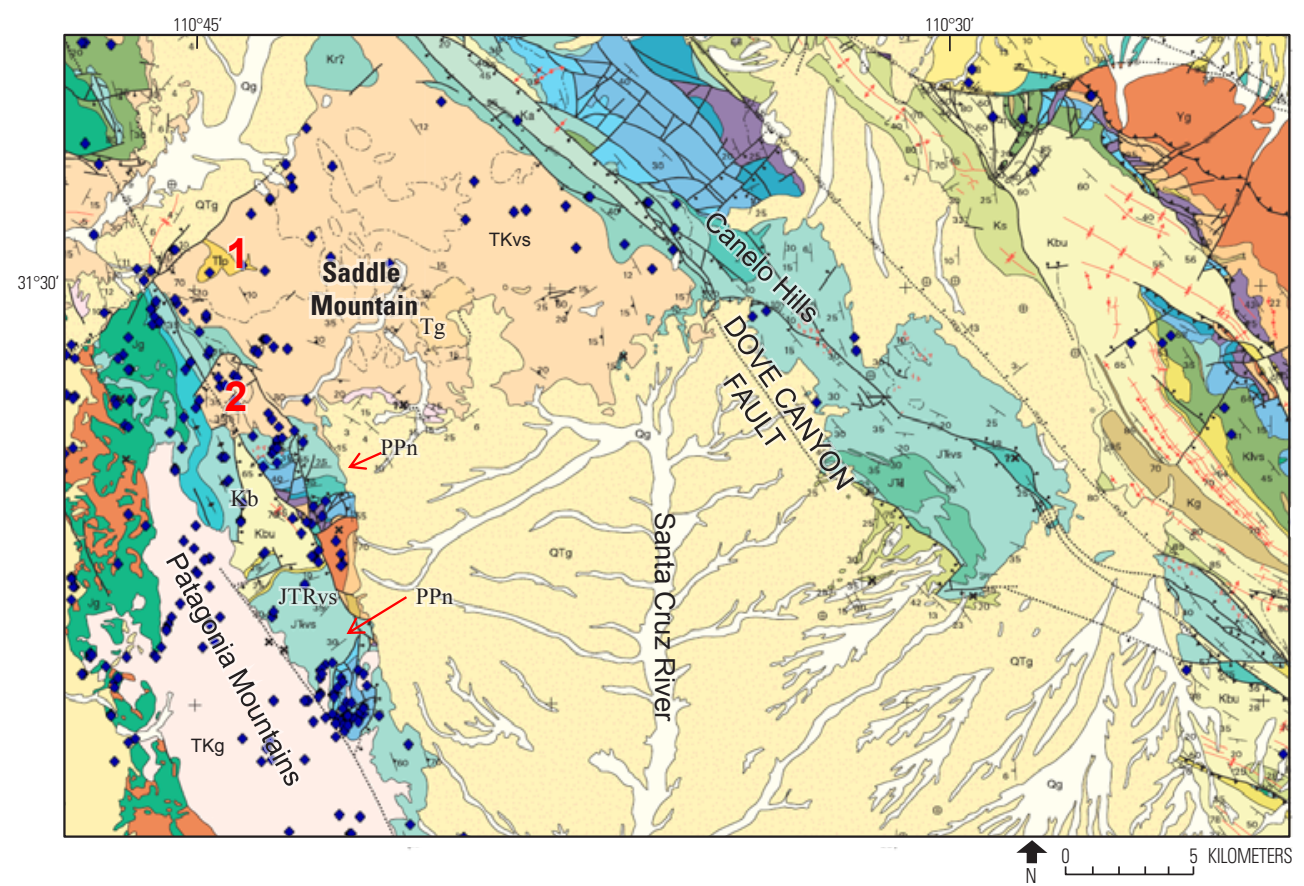

Figure 10. Geologic map of the San Rafael Basin, southeast Arizona with basin depth contours (contour interval, $0.1 \mathrm{~km}$ ) based on a gravity model (Bultman, 1999). Red x's, gravity stations. Red lines, locations of ground based magnetic field profile data acquisition for candidate lithologies; magenta lines, target sites; brown lines, paths over which profiles 1 and 2 were acquired. Descriptions of important map units are listed in table 1. Geology from Drewes and others (2002). Red circles, exploration wells that did not reach bedrock (Arizona Department of Water Resources, 2009) with depths (in feet) indicated.

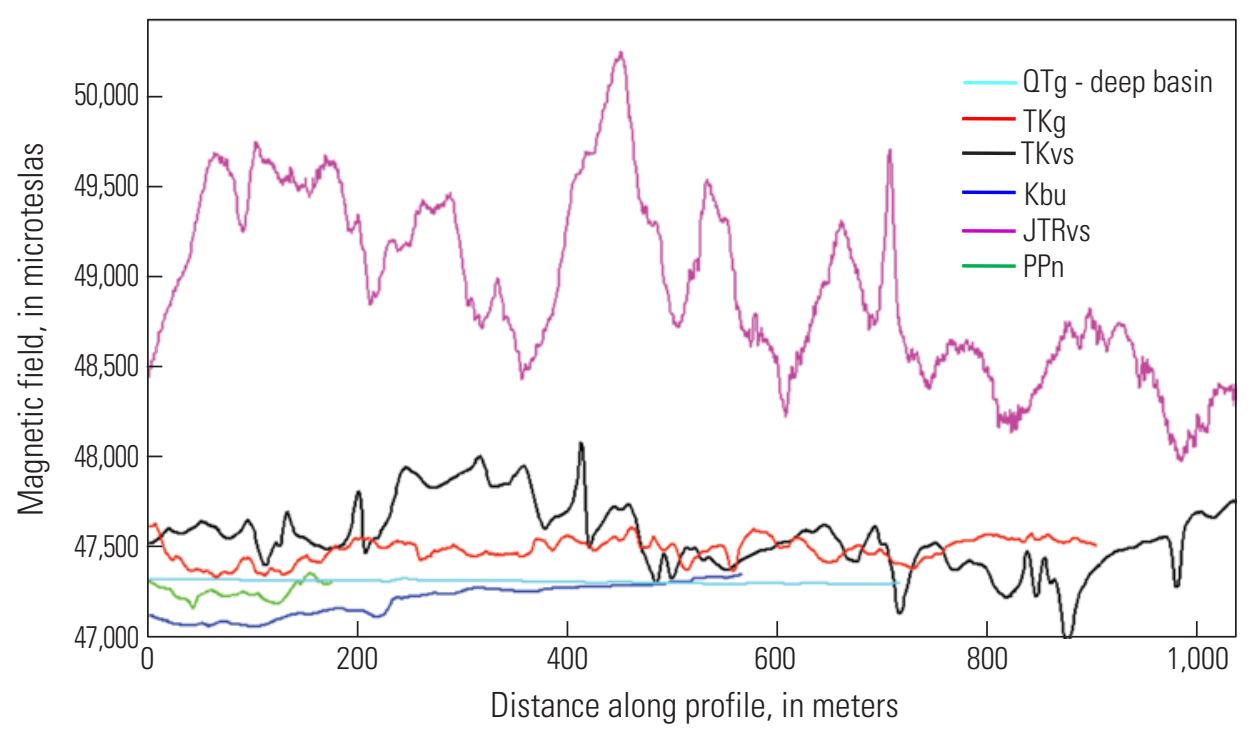

Figure 11. Plot showing heading corrected magnetic signatures of candidate lithologies and deep basin fill in the San Rafael Basin, southeastern Arizona (figs., 7 and 8). See table 1 for definitions of map units. 
Table 1. Explanation of selected map units.

[After Drewes (1996) and Drewes and others (2002) except where noted]

\begin{tabular}{|c|c|}
\hline Map unit (fig. 8) & Explanation \\
\hline$\overline{\mathrm{Qg}}$ & $\begin{array}{l}\text { Younger surficial deposits (Pleistocene and Holocene) - Gravel and silt in Alluvial pediments; includes some colluvium and } \\
\text { soils. Deposits mostly light gray, unindurated, and of poorly rounded and locally derived clasts, except along larger valley- } \\
\text { center rivers. Mostly several meters but as much as } 100 \mathrm{~m} \text { thick. }\end{array}$ \\
\hline QTg & $\begin{array}{l}\text { Gravel, sand, and conglomerate (Miocene through Holocene)-Alluvium filling intermontaine basins, on pediments, in } \\
\text { alluvial aprons and stream terraces, and along watercourses. }\end{array}$ \\
\hline $\operatorname{Tg}$ & Pyroxene monzonite (after Simons, 1974). \\
\hline TKvs & $\begin{array}{l}\text { Volcanic and sedimentary rocks (Late Cretaceous through Eocene)_-Andesite flows and breccia sheets. Primarily } \\
\text { trachyandesite north and northwest of the San Rafael Basin. }\end{array}$ \\
\hline $\mathrm{Kbu}$ & $\begin{array}{l}\text { Bisbee Formation Group, undifferentiated (Early Cretaceous) - Upper part of the Bisbee Formation or Group, } \\
\text { undifferentiated, and related rocks, consisting of brownish- to reddish-gray arkose, siltstone, sandstone, conglomerate, and } \\
\text { some fossiliferous gray limestone. Commonly several hundred meters thick. }\end{array}$ \\
\hline PPn & $\begin{array}{l}\text { Naco Group (Pennsylvanian and Early Permian)_-Mainly limestone and dolomite; some siltstone, sandstone, and } \\
\text { marlstone. }\end{array}$ \\
\hline
\end{tabular}

unit TKg where its magnetic signature was acquired (fig. 10), has a high magnetic susceptibility or is underlain by rocks with a high magnetic susceptibility. Although the mean of its magnetic signature is nearly 2,000 nT higher than those of the others units, map unit JTRvs is most distinguished by its high-amplitude magnetic anomalies, which may be due to differing magnetic susceptibilities or the remanent magnetism of individual flows within the unit, or to groups of diorite dikes that occur in the study area. Candidate-lithology map unit PPn is locally significant for hosting replacement-mineral deposits. Specifically, where the ground-based magnetic-field-profile data were acquired, the underlying lithology is the Colina Limestone. Roads in the study area where this map unit crops out allowed only about $160 \mathrm{~m}$ of ground-based magnetic-field-profile data to be acquired.

Three candidate lithologies (map units TKg, TKvs, JTRvs, fig. 8; table 1) have magnetic signatures with large amplitudes that might be identifiable while concealed under shallow basin fill, assuming a very low amplitude magnetic signature of the basin fill, similar to the signal from deep basin fill (map unit QTg, fig. 11). Map unit Kbu could not be detected under basin fill but might be identifiable by the absence of a high-amplitude magnetic signal in shallow parts of the basin. Map unit PPn has a moderately high amplitude magnetic signature, and its texture differs from that of map unit $\mathrm{TKg}$, which has a similarly high amplitude magnetic signature but too short a profile to be characterized. Because map unit PPn consists of non magnetic limestone, its moderate-amplitude magnetic signal may be due to alteration and replacement within the limestone.

A gridded aeromagnetic map of the San Rafael Basin (fig. 12) shows several immediately apparent features, including a major magnetic high centered near Saddle Mountain (fig. 8) and extending eastward, a southeast-trending magnetic low that follows the Canelo Hills (fig. 8), and a magnetic high in the southern Patagonia Mountains (fig. 8). A northwest-trending magnetic low is associated with volcanic rocks in the Canelo Hills. If an intrusive body is responsible for the Saddle Mountain magnetic high, this feature may extend at depth southward under the San Rafael Basin to with about $5 \mathrm{~km}$ north of the United States-Mexican border. The Red Mountain porphyry copper system occurs on a relative magnetic high, and the Sunnyside porphyry system lies near the center of a major magnetic low. Note that the range of magnetic anomalies is about $450 \mathrm{nT}$, much less than the range of more than 3,000 nT in the ground-based magnetic-field-profile data in figure 11 and omitting data from the Saddle Mountain high shown in figure 12.

As mentioned above, two target sites in the San Rafael Basin have been chosen to demonstrate the magnetic-fieldprofile method for estimating concealed lithology. The first target site $(1$, figs. 10,12$)$ is in the southwestern part of the basin, and the second target site is in the northern part of the basin and comprises two subsites (2a, 2b, figs. 10, and 12). Although large magnetic anomalies are visible in figure 12, no textural information, such as that shown in figure 11, is available to help differentiate exposed or concealed lithologies. Only on the basis of the surrounding geology (fig. 10), the concealed lithology at site 1 is assumed to be map unit JTRvs. The second target site was split into two subsites so that the effects of two different depths could be observed. The depth to bedrock was estimated to be shallow in these areas, approximately $50 \mathrm{~m}$ for target sites 1 and $2 \mathrm{a}$ and at least $100 \mathrm{~m}$ for target site $2 \mathrm{~b}$ (fig. 10). Although the gravity-based depth model shown in figure 10 would indicate that bedrock is at a depth of $400 \mathrm{~m}$ at target site $2 \mathrm{~b}$, the ground-based magnetic-field-profile has a large-amplitude, short-wavelength component at this site that suggests a depth nearer to $100 \mathrm{~m}$. Initially, concealed geology was interpreted 
to be map unit TKvs at target sites $2 \mathrm{a}$ and $2 \mathrm{~b}$, owing to the proximity of outcrops of map unit TKvs to the north and aeromagnetic information from figure 12.

Ground-based magnetic-field-profile data acquired over shallow basin fill contain one signal component from the basin fill and another from the underlying bedrock lithology in some cases. If the amplitude of the signal component from the concealed lithology dominates the texture of the total magnetic signal acquired over basin fill, the choices of potential concealed lithologies from the list of candidate lithologies may be narrowed. In addition, any candidate lithologies whose magnetic are indistinguishable from that of the basin fill (those with very low amplitudes) can be eliminated. Graphical analysis, descriptive statistics, the power spectrum, and the multifractal spectrum of the ground-based magnetic-field-profile data have all been shown to contribute information that may help in identifying a concealed lithology (Bultman and Gettings, 1994; Bultman, 1999; Gettings, 1999, 2002, 2008).

\section{Graphical Analysis and Descriptive Statistics of Ground-Based Magnetic-Field-Profile Data}

In order to compare the magnetic signatures of candidate lithologies with the ground-based magnetic-field-profile data acquired over basin fill at a target site, both the original data and upward-continued (by their estimated depth of burial) data from a candidate lithologies were plotted to allow visual comparison of the mean and the textural properties of the magnetic signal. If the mean of the magnetic signature of a candidate lithology and the magnetic signal from a target site drastically differ, the candidate lithology under consideration may not be the concealed lithology, although statistical mean values can be highly influenced by rock at depth. If the magnetic anomalies from a target site's magnetic signal are higher in amplitude than the magnetic signal from a candidate lithology, that candidate lithology can be eliminated as a concealed lithology because upward continuation will always reduce the heights of magnetic anomalies.

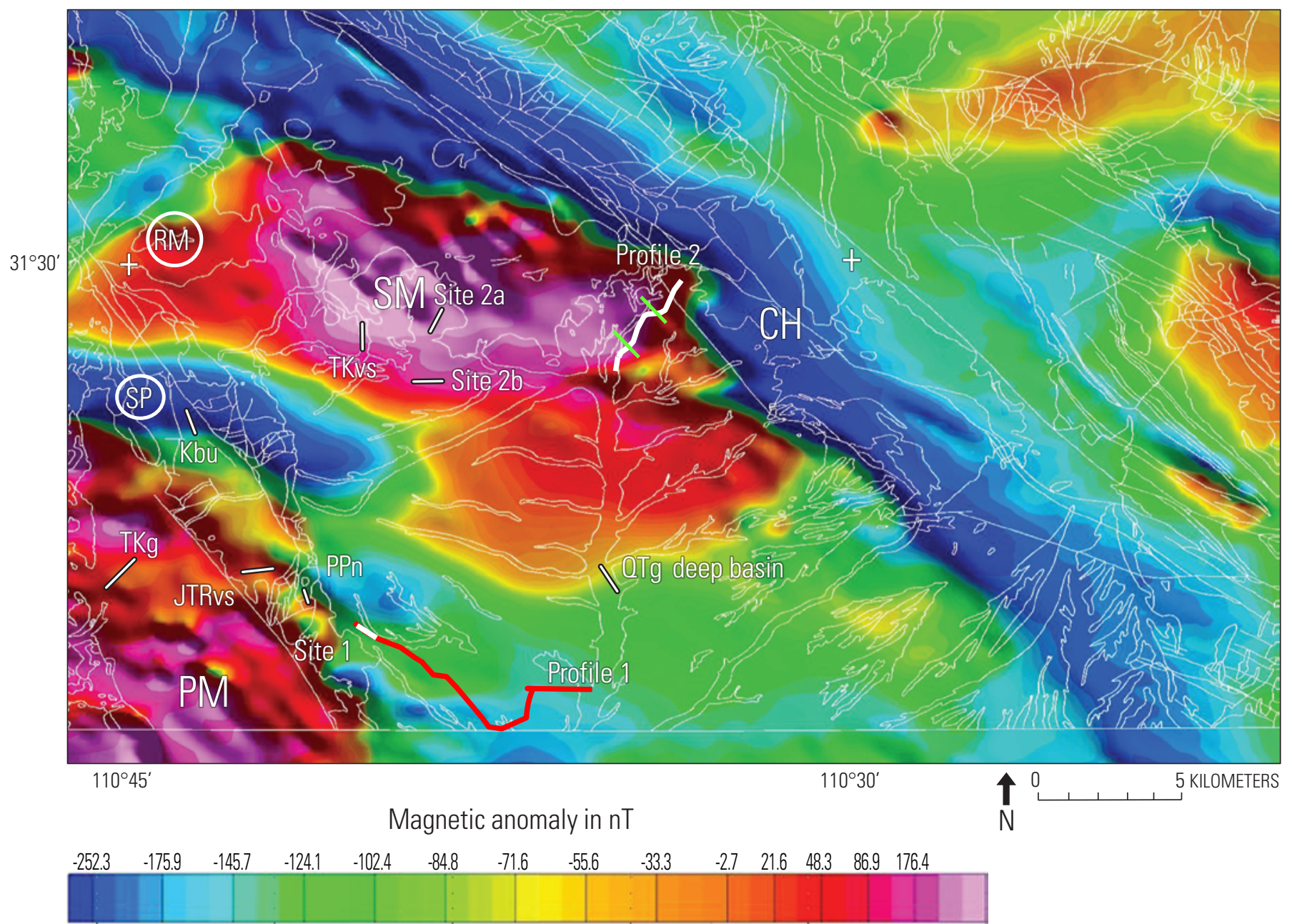

Figure 12. Plot showing decorrugated heading corrected magnetic signatures of candidate lithologies and deep basin fill in the San Rafael Basin, southeastern Arizona. 
Textural measures, such as the number of peaks per kilometer, can also be compared. Upward continuation will always reduce the number of peaks per kilometer (it is a low-pass filter), and so that information can be included in the analysis. Although this qualitative analysis helps with initial estimates of concealed lithology, these descriptive statistics provide a more quantitative basis for comparison.

Descriptive statistics are used to quantitatively characterize the magnetic signatures of candidate lithologies and the magnetic signal from a target site, in an attempt to quantify the appearance or texture of the data with several measures that can then be compared. Useful measures include (1) the number of peaks per distance along the profile $(p / x),(2)$ the Euclidean vector signal length $(V)$ over distance along the profile $(V / x)$, (3) the mean peak height (MPH), (4) the mean peak half-width (MPHW), (5) the signal variance, (6) the signal range, and (7) the signal mean (Bultman and Gettings, 1994; Bultman, 1999; Gettings, 1999, 2002, 2008). In this analysis, the number of peaks was calculated by using a routine that selects anomalies with a minimum signal height and width in order for a magnetic-signal component to be designated as a peak. Unless otherwise noted, those values are $10 \mathrm{nT}$ and $5 \mathrm{~m}$, respectively; they characterize the high-frequency components that are included in ground-based magnetic-field-profile data yet are large enough that most system noise is discarded.

The Euclidean vector signal length of ground-based magnetic-field-profile data is defined as

$$
V=\Sigma_{i}\left\{\left(B_{i}-B_{i+1}\right)^{2}+\left(x_{i}-x_{i+1}\right)^{2}\right\}^{1 / 2}
$$

where $B$ is the Earth's total-intensity magnetic field (in nanoteslas) at an observation point and $x$ is the distance (in kilometers) from the start of signal from which this point was observed. Thus, the units of $V$ are the square root of the sum of nanoteslas squared plus kilometers squared $\left(\sqrt{\mathrm{nT}^{2}+\mathrm{km}^{2}}\right)$.

Candidate lithologies with high-amplitude magnetic signals display large values of MPH, $p / x, V / x$, and signal variance and range. The signal mean, which can be a reflection of the magnetic susceptibility of each map unit, can be important to distinguish both exposed and concealed lithologies, but as mentioned above, the signal mean can also depend on the magnetic susceptibility of underlying materials, and so care must be taken when this statistic is used. In some cases, these statistics can uniquely define candidate lithologies, but the statistics change drastically when a lithology is concealed by basin fill, primarily owing to the depth of concealment but also to the addition of the magnetic signal due to the basin fill.

The descriptive statistics for each of the candidate lithologies used in this study differ significantly (table 2). The magnetic signatures derived from lithologies with highamplitude magnetic anomalies include map units TKg, TKvs, and JKvs (table 1), all of which have high values of MPH, $p / x$, $V / x$, and signal variance and range and so are referred to as high-amplitude candidate lithologies. Map unit $\mathrm{Kb}$ is generally less magnetic than the other lithologies and has low values of $\mathrm{MPH}, p / x$, and signal variance and range. Map unit PPn, which has a short signal length due to small exposure in outcrop, and moderate values of MPH, $p / x, V / x$, and signal variance and range, consists primarily of limestone but is altered and hosts mineral deposits in the area where the data were acquired, and so the magnetic signal from this lithology may be due to alteration and replacement.

The MPHW value is nonlinearly related to the depth of burial of the magnetic sources. If the sources are dipping sheets, however, the MPHW value is strongly correlated to the depth of the sources, indicating that they are shallow except in the basin fill. The signal from the deep basin fill, which was obtained in an area with nearly $1,000 \mathrm{~m}$ of basin fill (fig. 10), shows very low values of MPH, $p / x, V / x$, and signal variance and range and a moderate to high mean. The high mean for this profile may indicate high-susceptibility bedrock concealed at depth.

The less magnetic lithologies and the basin fill tend to have much broader magnetic anomalies, indicating that the anomalies are coming from a greater depth than those of the high-amplitude lithologies. The value of the variable $p$, the number of peaks, which is a function of signal length and characteristics, is included to indicate that the mean and other values derived from $p$ could be misleading for signals acquired over short distances.

Table 2 also shows how these statistics change when candidate lithologies are upward continued. Upward continuation is a low-pass filter, and so much of the information content in a signal is removed after upward continuation. Because these statistics are greatly changed, they generally are useless for identification of a concealed lithology, although they may provide boundary conditions for such an estimation. When a lithology is concealed, the values of MPH, $p / x, V / x$ and signal variance and signal range will always be less than those obtained when the lithology is exposed at the surface. The MPHW value will generally increase when lithology is upward continued, and the signal mean will change little and should be considered constant. The mean is not listed in table 2 because with these short profiles its value after continuation is strongly affected by what is happening at the tails of the profile.

\section{The Power Spectrum of Ground-Based Magnetic-Field-Profile Data}

In addition to the statistics described above, the power spectrum of ground-based magnetic-field-profile data was used to characterize the magnetic signature of a candidate lithology of a target site. For a given profile, the power spectrum provides a plot of the portion of a signal's power (energy per unit distance) for a given wavenumber, calculated by using the discrete Fourier transform, which requires that the signal be equally spaced and spatially stationary (no trends). Equal spacing was accomplished by interpolating the data to a $1-\mathrm{m}$ interval, which preserved the signal shape in all cases and allowed these spectra to be presented with wavenumber units of inverse meters $\left(\mathrm{m}^{-1}\right)$. All spectra were equally smoothed 
Table 2. Descriptive statistics for candidate lithologies and deep basin fill.

[See table 1 for description of map units, and text for description of target sites; $x=$ Distance (in kilometers) along ground-based magnetic-field-profile; $p=$ Number of peaks in ground-based magnetic-field-profile data; $V=$ Euclidean length of ground-based magnetic-field-profile signal (in $\sqrt{\mathrm{nT}^{2}+\mathrm{km}^{2}}$ ); $B=\mathrm{Earth}^{\prime}$ t total-intensitymagnetic-field data acquired as ground-based magnetic-field-profile data; MPH = Mean anomaly peak height (in nanoteslas); MPHW = Mean peak half-width (peak to trough) (in meters); * The mean of upward-continued data depends on the tails of the upward-continued data and has little meaning for these short profiles; Peak designation was based on a minimum amplitude of $10 \mathrm{nT}$ and a minimum width of $5 \mathrm{~m}$; Some upward-continued data were omitted because for some lithologies the upward-continued data become too smooth to find peaks; For "deep basin," $5 \mathrm{nT}$ and $3 \mathrm{~m}$ were used for peak height and minimum width, respectively, owing to the low amplitude of the signal.; Target site 2a data smoothed with running mean 5 due to much high-frequency noise — andesite; For target sites 1, 2a, and 2b, minimum peak height $=35 \mathrm{nT}$, and minimum peak half-width $=20 \mathrm{~m}$ (removes much of signal from basin fill.)]

\begin{tabular}{|c|c|c|c|c|c|c|c|c|c|}
\hline Map unit or target site & $p$ & $\begin{array}{c}x \\
(\mathrm{~km})\end{array}$ & $\begin{array}{c}p / x \\
(\text { per } k m)\end{array}$ & $\frac{V / \mathbf{x}}{\left(\sqrt{\mathrm{nT}^{2}+\mathrm{km}^{2}} / \mathrm{km}\right)}$ & $\begin{array}{c}\text { MPH } \\
(\mathrm{nT})\end{array}$ & $\begin{array}{l}\text { MPHW } \\
\text { (m) }\end{array}$ & $\begin{array}{c}\text { Stan. Dev. B } \\
\text { (nT) }\end{array}$ & $\begin{array}{c}\text { Range } B \\
\text { (nT) }\end{array}$ & $\begin{array}{c}\text { Mean } B \\
(\mathrm{nT})\end{array}$ \\
\hline Qg, QTg & 4 & 0.717 & 7.0 & $6.1 \mathrm{E}+04$ & 16 & 146 & 9.3 & 35 & 47,314 \\
\hline $\mathrm{TKg}$ up continued $25 \mathrm{~m}$ & 5 & 0.920 & 6.6 & $1.5 \mathrm{E}+05$ & 36 & 90 & 25.7 & 97 & $*$ \\
\hline TKg up continued $50 \mathrm{~m}$ & 3 & 0.920 & 4.4 & $6.6 \mathrm{E}+04$ & 24 & 144 & 14.2 & 53 & $*$ \\
\hline TKvs up cont. $25 \mathrm{~m}$ & 4 & 1.150 & 4.3 & $6.0 \mathrm{E}+05$ & 149 & 276 & 139.9 & 527 & $*$ \\
\hline TKvs up cont. $50 \mathrm{~m}$ & 4 & 1.150 & 2.6 & $4.1 \mathrm{E}+05$ & 185 & 231 & 116.3 & 457 & $*$ \\
\hline Kbu & 5 & 0.556 & 11 & $3.7 E+05$ & 35 & 33 & 93.8 & 287 & 47,203 \\
\hline JTVs & 15 & 1.047 & 15 & $2.1 \mathrm{E}+07$ & 572 & 31 & 478.7 & 2278 & 48,906 \\
\hline PPn ${ }^{1,2}$ & 6 & 0.157 & 44 & $1.2 \mathrm{E}+06$ & 71 & 15 & 31.5 & 130 & 47,164 \\
\hline Site 1 ( $\sim 50 \mathrm{~m}$ depth to bedrock) & 5 & 0.894 & 6.7 & $1.3 \mathrm{E}+06$ & 212 & 85 & 93.1 & 424 & 48,803 \\
\hline Site $2 \mathbf{a}(\sim 50 \mathrm{~m}$ depth to bedrock) & 7 & 0.796 & 10 & $6.7 E+06$ & 149 & 32 & 67.6 & 401 & 50,496 \\
\hline Site $\mathbf{2 b}(\sim 100+\mathrm{m}$ depth to bedrock $)$ & 8 & 1.397 & 6.4 & $6.8 \mathrm{e}+05$ & 129 & 105 & 64.9 & 307 & 49,273 \\
\hline
\end{tabular}

${ }^{1}$ The location data for map unit PPn were smoothed by a running-mean filter of length 21 sample points for heading correction due to poor GPS reception. The road representation was good.

${ }^{2}$ The short length of this profile prevented upward continuation of map unit PPn.

with a Daniell filter (Bloomfield, 2000) with window widths of length 5 and 3 . The smoothing, which is similar to a running mean, removes excessive noise from the power spectra without changing their shape.

The ground-based data were acquired at $10 \mathrm{~Hz}$, and so driving at a maximum speed of $72 \mathrm{~km} / \mathrm{h}(20 \mathrm{~m} / \mathrm{s}, \sim 45 \mathrm{mi} / \mathrm{h})$ produces a sampling interval of $2 \mathrm{~m}$. The speed of the vehicle while acquiring data was kept to $72 \mathrm{~km} / \mathrm{h}$ or less in all cases. In general, speeds are kept to less than $50 \mathrm{~km} / \mathrm{h}(\sim 14 \mathrm{~m} / \mathrm{s}$, 1.4-m sampling interval, $\sim 30 \mathrm{mi} / \mathrm{h})$. Choosing a cutoff wavelength of $4 \mathrm{~m}$ is therefore reasonable, which means that the power spectrum for wavenumbers greater than about 0.25 is ambiguous.

The power spectra for the five candidate lithologies and the deep basin fill are plotted in figure 13. In general, the high-amplitude magnetic signatures display the highest power throughout their spectra. Map unit JTRvs displays the most power at all wavenumbers but less power with decreasing wavenumber relative to the other map units. Map unit TKvs has a higher power than map unit TKg at low wavenumbers, and a similar power at high wavenumbers. Map unit Kbu has a low power at all wavenumbers, and the highly nonmagnetic basin fill has less than a hundredth of the power at very low wavenumbers and less than a thousandth of the power at higher wavenumbers. In addition, the shape of these spectra at low wavenumbers is nonlinear, indicating that power-law scaling may be useful in describing the texture or characteristics of the ground-based magnetic-field-profile data. The shape of these spectra of the magnetic signature of each candidate lithology and the relations between spectra will help distinguish lithologies concealed at depth by nonmagnetic basin fill, again by establishing boundary conditions for each candidate lithology. 
The power spectrum for a candidate lithology (here, map unit TKvs) when the acquired signal is upward continued is plotted in figure 14. The upward-continued spectra rapidly decrease in power at all wavenumbers, and rapidly increase in slope at very low wavenumbers. The low-pass-filter feature of the upward-continuation process creates spectra of lower power and with power concentrated in long-wavelength anomalies. From these observations, any concealed lithology must have a power spectrum that is lower in power at all wavenumbers than its candidate lithology. Although the spectrum for map unit TKvs upward continued $10 \mathrm{~m}$ shows a lower power than that for map unit TKvs upward continued $25 \mathrm{~m}$ at wavenumbers in the vicinity of 0.28 , this change occurs beyond the cutoff wavenumber of 0.25 . On the basis of figure 13, power added to the signal from basin fill will be insignificant because this power is generally less than a thousandth of the power from a high-amplitude candidate lithology.

\section{The Multifractal Spectrum of Ground-Based Magnetic-Field-Profile Data}

The fractal dimension of a signal, which describes how that signal fills the space that it occupies, is characterized by noninteger dimensions. Multifractal objects display a differing fractal dimension, depending on differing scaling exponents (Feder, 1989). Multifractal analysis therefore provides information on the spectrum of fractal dimensions required to characterize how a multifractal object fills the space that it occupies.

Multifractal scaling has been demonstrated in many geologic processes, including porosity measurements derived from neutron density logs; borehole resistivity; density and natural gamma-ray borehole logs; magnetic susceptibility from borehole logs (Pilkington and Todoeschuck, 1993); aeromagnetic-field-profiles (Pilkington and Todoeschuck, 1993); the distribution of faults, fractures, and joints; the
Figure 13. Plot showing power spectra of candidate lithologies and deep basin fill in the San Rafael Basin, southeastern Arizona.

Figure 14. Plot showing power spectrum of map unit TKvs, upward continued 10, 25, 50, and $100 \mathrm{~m}$.
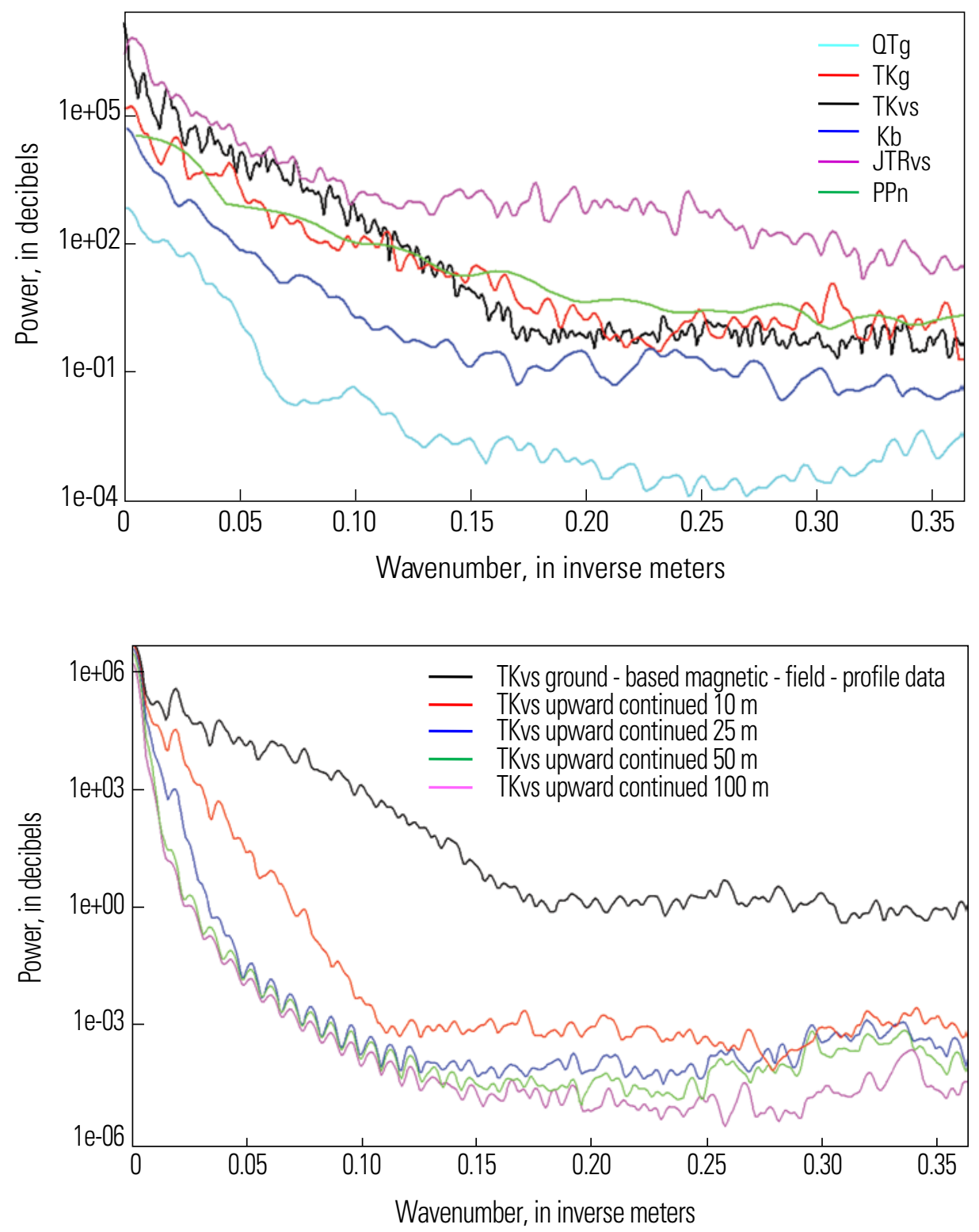
sizes and spatial distribution of ore deposits; the topographic shape of the Earth's surface; and closely spaced Earth's totalintensity-magnetic-field data (Gettings and Bultman, 1997).

Several workers (Pilkington and Todoeschuck, 1993; Lovejoy and others, 2001; Pecknold and others, 2001; Gettings, 1995, $2004,2005,2006)$ have shown that magnetic-susceptibility distributions in drillhole logs exhibit multifractal behavior. Gettings (2005) constructed a physical fracture-diffusion model that explains the multifractal distribution of the magnetic susceptibilities of hydrothermally altered rocks. Lovejoy and others (2001) and Pecknold and others (2001) showed that anisotropic multifractal distributions describe the three-dimensional distribution of magnetization within the Earth. The spatial distribution of lithology has been modeled with fractals (Maus and Dimri, 1996; Dolan and others, 1998). Multifractal models thus provide a natural way to describe the distribution of magnetic sources in the Earth's crust.

A multifractal can be considered as an assemblage of independent monofractals, each with its own dimension. A multifractal distribution can be determined from box counting as follows. A set consisting of $N_{T}$ points distributed in space will have $N(\delta)_{i}$ points in the $i$ th box, the size of the box being defined by the box side length $\delta$. The product $\delta \bullet N(\delta)_{i}$ defines a measure of the set $N$. Then $\mu_{i}$ denotes the relative weight (probability) of the measure within the $i$ th box with respect to the total number of points in the set $N_{T}$ :

$$
\mu_{i}=\frac{N(\delta)_{i}}{N_{T}} .
$$

A $q$ measure can be defined as (Feder, 1988; Falconer, 1990; Berkowitz and Hadad, 1997):

$M_{q}=\lim _{\delta \rightarrow 0} \inf _{\delta_{i}<\delta} \sum_{i=1}^{N(\delta)} \mu_{i}^{q} \delta_{i}^{d}=N(q, \delta) \delta^{d} \rightarrow\left\{\begin{array}{l}0, d>\tau(q) \\ \infty, d>\tau(q)\end{array}\right.$,

where $d=\tau(q)$ and

$$
N(q, \delta)=\sum_{i=1}^{N(\delta)} \mu_{i}^{q} .
$$

$M_{q}$ is finite and nonzero only if $d=\tau(q)$; therefore (Berkowitz and Hadad, 1997),

$$
M_{q}=\lim _{\delta \rightarrow 0} N(q, \delta) \cdot \delta^{\tau(q)} .
$$

The mass exponents $\tau(q)$, which control how the moments of the probabilities $(\mu)$ scale with differing $\delta$, can be estimated from equation 5 by plotting $\log (1 / \delta)$ versus $\log (\mathrm{N}(q, \delta))$ for each $q$ value:

$$
\log N(q, \delta)=\log M_{q}+\tau(q) \cdot \log \left(\frac{1}{\delta}\right) .
$$

If the plot is reasonably linear, $\tau(q)$ is the estimated linear slope of the plotted points.
The Lipschitz-Holder exponent $\alpha$ defines the scaling of probabilities $\left(\mu_{1}\right)$ as a function of box size $\left(\delta_{1}\right)$ for the $i$ th box (Feder, 1988):

for

$$
\mu_{i} \propto \delta_{i}^{a_{i}} \text { for } \alpha_{i}>0
$$

where $\alpha_{1}$ represents the fractal dimension for the $i$ th box and can vary from place to place. The number of boxes required to cover a subset in the range between $\alpha$ and $\alpha+d \alpha$ is defined by (Feder, 1988; Berkowitz and Hadad, 1997):

$$
N(\alpha, \delta)=\rho(\alpha) d \alpha \cdot \delta^{-f(\alpha)},
$$

where $\rho(\alpha) d \alpha$ denotes the number of subsets between $\alpha$ and $\alpha+d \alpha$ and $\mathrm{f} 9 \alpha$ and $f(\alpha)$ represents the fractal dimension of each of the $\alpha_{1}$ subsets.

From equation 3, the $q$ measure of the complete set can be defined as follows (Feder, 1988; Falconer, 1990; Berkowitz and Hadad, 1997)

$$
M_{q} \propto \lim _{\delta \rightarrow 0} \int_{\alpha=0}^{\infty} d \alpha \cdot \delta^{q \alpha+\tau(q)-f(\alpha)} .
$$

The solution to equation 9 by the steepest-descent method in the limit of small $\delta$ yields (Feder, 1988; Falconer, 1990; Berkowitz and Hadad, 1997):

$$
M_{q}=\lim _{\delta \rightarrow 0} \delta[\alpha \cdot q+\tau(q)-f(\alpha)],
$$

where $=f^{\prime}(\alpha(q))=q$ and where $M_{q}$ is finite if:

$$
f(\alpha)=\alpha \cdot q+\tau(q) .
$$

Equation 11 is valid for every $q$, and so its derivative with respect to $q$ is:

$$
\alpha=\frac{-d}{d q} \tau(q) .
$$

Equations 11 and 12, the Legendre transform, define $f(\alpha)$ once $\tau(q)$ is known. $\tau(q)$ is obtained from equation 6 , and $f(\alpha)$ is referred to as the singularity spectrum or multifractal spectrum.

The $f(\alpha)$ curve achieves its maximum value at $f(\alpha(q=0))$. This point, which is the most probable singularity subset, describes the fractal dimension of the geometric support of the multifractal set (Feder, 1988). Because all minerals have some magnetic susceptibility, a support dimension of 1.0 is observed in ground-based magnetic-field-profile data. The $f(\alpha)$ curve equals zero at the two extremes of $\alpha, \alpha_{\max }$ and $\alpha_{\min }$, which are related to $q$ approaching negative infinity and positive infinity, respectively. For many real-world variables, these values may not be calculable, depending on the type of data, but may be approximated from the shape of the $f(\alpha)$ curve. Multifractals with a large $\alpha_{\max }-\alpha_{\text {min }}$ are commonly said to have more strength than multifractals with a smaller $\alpha_{\max }-\alpha_{\text {minn }}$. A point known as the measure concentrate (Berkowitz and Hadad, $1997)$ occurs at $f(\alpha(q=1))$, where $f(\alpha)=\alpha$ and $f(\alpha)=1$. 
The multifractal spectra of the magnetic signature from each of the candidate lithologies, calculated by using box counting based on the Legendre transform in FRACLAB (Lévy-Véhel and Legrand, 2004), are plotted in figure 15. These spectra demonstrate that the multifractal spectrum can differentiate the magnetic signatures of exposed lithologies on the basis of ground-based magnetic-field-profile data. Each candidate lithology and the basin fill have a unique multifractal spectrum that is distinguishable by the $\alpha$ location of $f(\alpha)=1$, the width of the spectrum in $\alpha\left(\alpha_{\max }-\alpha_{\text {min }}\right.$, its strength), and the general shape of the spectrum (symmetrical, right or left skew).

Map unit JKvs has the lowest value $(0.72)$ at $f(\alpha)=1$; its spectrum is also much weaker than those of the other map units and is slightly right skewed. Map unit TKvs is differentiated from the others by $\alpha=0.81$ at $f(\alpha)=1$, by its strength, and by its symmetrical form. Map unit TKg is differentiated from the other candidate lithologies by its spectrum reaching the support dimension $f(\alpha)=1$ at $\alpha=0.78$ and by its spectrum being weaker than that of map unit TKvs and only slightly stronger than that of map unit JRvs. The rest of the spectra can be similarly discriminated. None of these spectra extends to $f(\alpha)=0$, simply because no data are available at very large $(q<0)$ and very small $(q<0)$ box sizes to calculate these values.

The effect of upward continuation on the multifractal spectrum of ground-based magnetic-field-profile data is shown in figure 16 for map unit TKvs. Upward continuation tends to change the multifractal spectrum in two ways. First, increases for $f$ nonlinearly and the position of the entire curve moves to the right. Second, the left side (left of $f(\alpha)=1$ ) of the spectrum is increasingly removed with increasing upward continuation. Both of these changes result from to the loss of information in the magnetic-field profile associated with low-pass filtering due to upward continuation.

In equation $2, \mu_{l}$ denotes the relative weight (probability) of the measure within the $i$ th box with respect to the total number of points in the set $N_{T}$. In addition, equation 4 shows that $\tau(q)$ depends on $\mu_{l}^{q}$ and that the value of $f(\alpha)$ depends on $\tau(q)$. The net effect of these relations means that the farleft-hand side of the $f(\alpha)$-versus- $\alpha$ curve (where $q \rightarrow+\infty$ ) emphasizes boxes with more information. Because upward continuation acts as a smoothing filter on ground-based magnetic-field-profile data, removing more information from the signal with increasing upward continuation, $\tau(q)$ and, thus, $f(\alpha)$ become incalculable for signals with very low information content and high $q$ values. Also, as information is lost, the rest of the multifractal spectrum steepens to the left of the point where $f(\alpha)=1$, becoming weaker and less singular with increasing upward continuation. The shape of the right-hand parts of the spectrum, to the right of where $f(\alpha)=1$, is nearly unchanged but is offset by the offset value of $\alpha$ at $f(\alpha)=1$.

These changes in the multifractal spectrum with upward continuation have important implications for the estimation of concealed lithology. Owing to the loss of information content of the signal with upward continuation, the multifractal spectrum of a concealed lithology should tend to lose the far-left-hand side of the spectrum. The magnitude of this effect depends on the amplitude of the anomalies in the magnetic-field profile from the concealed lithology, which is also related to the depth of burial and requires a nonmagnetic basin fill. Therefore, if a lithology concealed by basin fill has a significant left-hand side of the multifractal spectrum visible, then this part of the spectrum may contain information from magnetic basin fill. The upper part and right-hand side of the multifractal spectrum best represent the concealed lithology upward continued to the depth of burial. Also, the relative positioning of the spectrum is important. If the right-hand side of the multifractal spectrum from a concealed lithology falls to the left of the right-hand side of the multifractal spectrum from a candidate lithology, then that candidate lithology can be eliminated from contention as the concealed lithology. Examples of these types of interpretation of the multifractal spectrum are given below in the real-world analysis of concealed lithologies.

\section{Caveats in the Estimation of Concealed Lithology}

Several potential problems contribute to the inability of the textural measures to consistently predict concealed lithology. The objective is to detect a magnetic signal from bedrock concealed by (nearly) nonmagnetic basin fill and to use the properties of that signal to determine the specific concealed lithology which generated it. The concealed lithology is chosen from several candidate lithologies that are possible geologic map units which may be concealed by basin fill on the basis of local geology, but the concealed lithology may not be a candidate lithology but some lithology that does not crop out in the region. In addition, U.S. geologic maps are based on a time-stratigraphic mapping

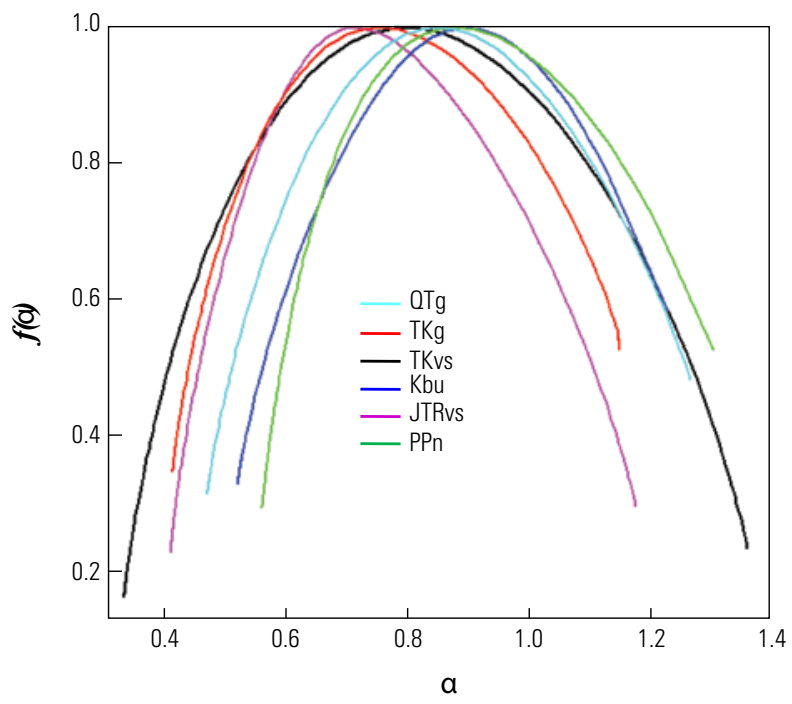

Figure 15. Plot showing multifractal spectra of ground-based magnetic-field-profile data acquired over exposed bedrock lithologies. 
system, whereby map units may contain more than one lithology, and so we need to understand the relations between map units and their inclusive lithologies in the study area. Once an area within a map unit is chosen as a candidate lithology, data is acquired over that area to define the magnetic signature of that candidate lithology. For instance, map unit JTRvs, to the east of the Patagonia Diorite (map unit TKg, fig. 8), is extremely magnetic; it likely contains several andesitic flows of varying composition, but in figure 11 it seems to display consistent textural properties over the area used to define its magnetic signature. In the Canelo Hills (figure 10), to the northeast of the basin, map unit JTRVs is predominantly siliceous tuff and has different magnetic properties displaying a much lower mean and low-amplitude anomalies.

The signal from bedrock acquired over basin fill also depends extremely on its depth of burial. As discussed above, the properties of this signal, including its power spectrum and its multifractal spectrum, vary greatly with depth of burial. An incorrect depth determination will cause problems when determining concealed lithology. In addition, many bedrock surfaces under basin fill are not perfectly level but display considerable relief, indicating that the bedrock surface over which the concealed lithology was acquired likely has differing depths of burial. Generally, this consideration cannot be taken into account without a detailed depth profile for the target site.

In aeromagnetic surveys, Cenozoic basin fill in the Southwestern United States is generally assumed to be nonmagnetic or very nearly nonmagnetic, but not for ground-based magnetic-field-profile data. As the TM data analysis has already shown, the surface composition of basin fill can vary significantly within a basin. Also, analysis of data from the target sites discussed below demonstrates that the magnetic properties of the basin fill are considerable in at least some places.

\section{Estimation of Concealed Lithology at Target Site 1}

Ground-based magnetic-field-profile data acquired over the basin fill at target site 1 were acquired just to the east of the basin-bedrock contact with map unit JTVvs (fig. 10). The depth of basin fill in this area is less than $100 \mathrm{~m}$ and was estimated at $50 \mathrm{~m}$ on the basis of the depth contours in figure 10. The bedrock-basin contact is exposed in a stream valley just west of the basin (fig. 2). The underlying map unit JKvs (andesite at this site) probably continues into the basin for some distance eastward, at least until a high-angle basin-margin fault occurs. The signal acquired over basin fill at target site 1 is plotted in figure 17 , along with the magnetic signature of the three high-amplitude candidate lithologies, map units JKvs, TKg, and TKvs. From this plot, map unit JKvs is likely the concealed geology for several reasons. First, the high mean of the concealed signal nearly matches the mean of map unit JKvs. Although this similarity could be due to an unknown high-magnetic-susceptibility lithology at depth, the mean almost exactly matches that of nearby exposed map unit JRvs. Second, as shown in figure 17, the amplitudes of the magnetic anomalies at target site 1 are too large to be from map unit TKvs or TKg, considering that the magnetic signal from the candidate lithology must be upward continued by $50 \mathrm{~m}$ for comparison. Both the $25-\mathrm{m}-$ and 50-m-upward-continued signals from map units TKvs

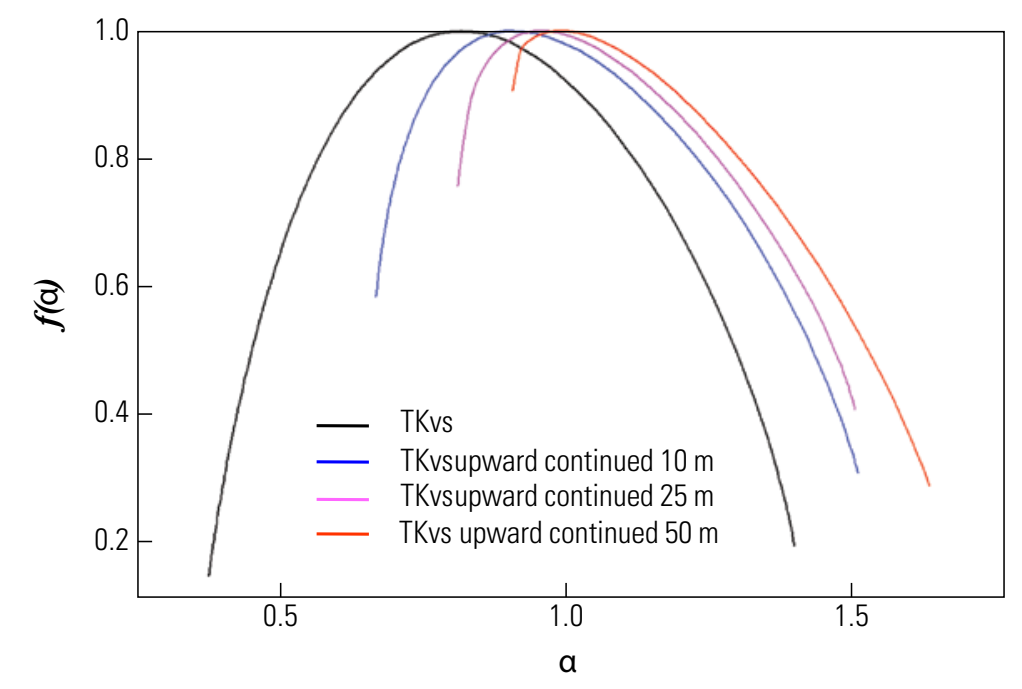

Figure 16. Plot showing multifractal spectrum of ground-based magneticfield-profile data acquired over exposed bedrock lithology (map unit TKvs) and upward continued 10, 25, and $50 \mathrm{~m}$.

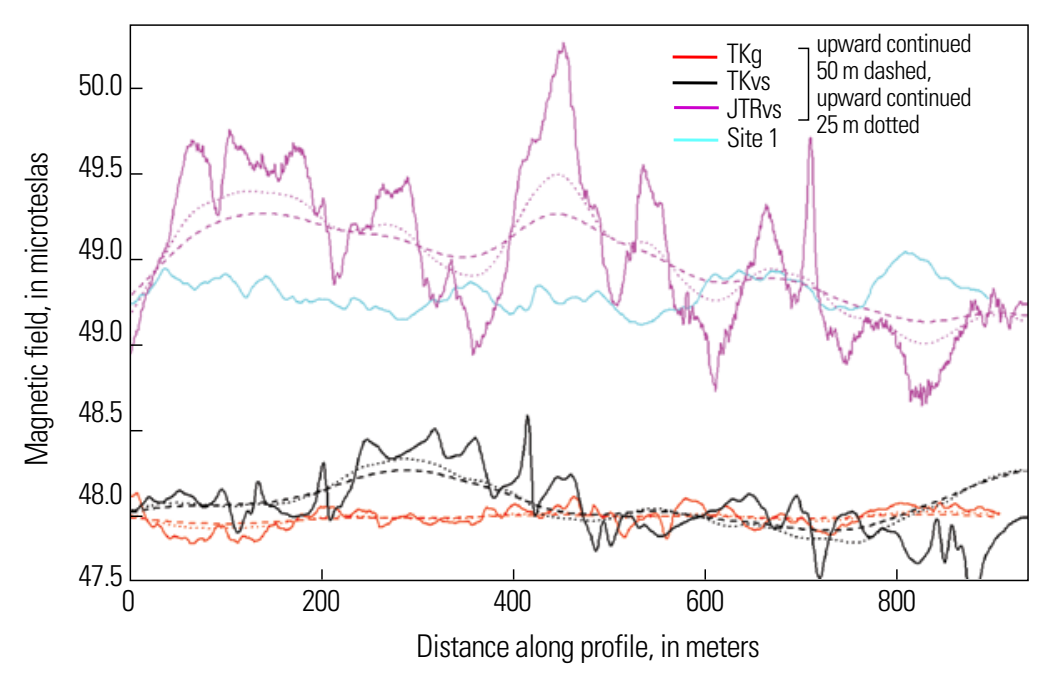

Figure 17. Plot showing ground-based magnetic-field-profile data over the three high-amplitude candidate lithologies, and upward continued 50 and 25 $\mathrm{m}$, and over basin fill at site 1 . 
and TKg have magnetic anomalies that are much too shallow and broad to match the magnetic signal from target site 1 . On the basis of figure 17, map unit JKvs is the only choice, but given the complexity of estimating concealed lithology, it is prudent to check all lines of evidence. Note how important simply plotting all the data is in the estimation of a concealed lithology. The plots summarize the descriptive statistics and allow textures to be easily differentiated.

The descriptive statistics for ground-based magneticfield-profile data acquired at target site 1 (and 2a and 2b) are listed in table 2. For the concealed target sites listed in table 2, the calculation of MPH values uses a minimum peak height of $35 \mathrm{nT}$ and peak half-width of $20 \mathrm{~m}$, eliminating the influence of basin-fill magnetic anomalies (shown in fig. 6), which generally are less than $35 \mathrm{nT}$, at least in the central part of the basin. The descriptive statistics for target site 1 are compared with the descriptive statistics of the candidate lithologies upward continued by $50 \mathrm{~m}$, the approximate depth of burial of bedrock at target site 1. From table 2, several descriptive statistics point to map unit JRvs being the concealed lithology, including the values of MPH, $V / x$, and mean $B$. On the basis of MPH values, the closest candidate lithology is map unit JKvs, and even for that lithology the MPH value at target site 1 is less than would be expected from map unit JRvs upward-continued $50 \mathrm{~m}$ (table 1), indicating that either the magnetic anomaly for map unit JKvs is less at target site 1 than measured on the exposed lithology, or that depth of burial is more than $50 \mathrm{~m}$. Only map unit JKvs has upward-continued $V / x$ values that could be comparable to those at target site 1 ; all other candidate lithologies have $V / x$ values that are too small after upward continuation. As shown in the graphical analysis, the mean value at the target site most closely matches that of map unit JTVv. The values of signal range and standard deviation listed in table 2 indicate that the candidate lithology is either is map unit JKvs or TKvs but is more likely map unit JRvs. MPHW and $p / x$ values from table 2 are not of much use. MPHW values in the upward-continued data become too large, owing to the smoothing effect of upward continuation. At target site 1, the MPHW values must contain some information from basin fill that tends to make them smaller. Although the data were filtered to remove information from magnetic anomalies with an MPH value of less than $35 \mathrm{nT}$ and an MPHW value of less than $20 \mathrm{~m}$, the MPHW values of the upward-continued candidate lithologies are larger than $20 \mathrm{~m}$. Likewise, the basin fill probably tends to make $p / x$ values higher at the target sites than for the upward-continued candidate lithologies.

The power spectrum from the ground-based magnetic-fieldprofile data acquired at target site 1 shows lower power at all wavenumbers only when compared with the power spectrum of map unit JTRVs, making this map unit the likely concealed lithology (fig. 18). The power spectra of the upward-continued candidate lithologies display much less power than that for target site 1 , indicating significant contributions to the magnetic signal from basin fill at all wavenumbers but especially those greater than 0.01 .

The multifractal spectrum from the ground-based magnetic-field-profile data acquired at target site 1 is compared with the multifractal spectra from the three high-amplitude candidate lithologies in figure 19. In figure 16, upward continuation tends to move the multifractal spectrum to larger values and removes data points from the left side of the spectrum, and so a signal from a concealed lithology should display these same properties. In figure 19, the left-hand side of
Figure 18. Plot showing power spectra of target site 1 and three high-amplitude candidate lithologies, and upward continued 25 and $50 \mathrm{~m}$.

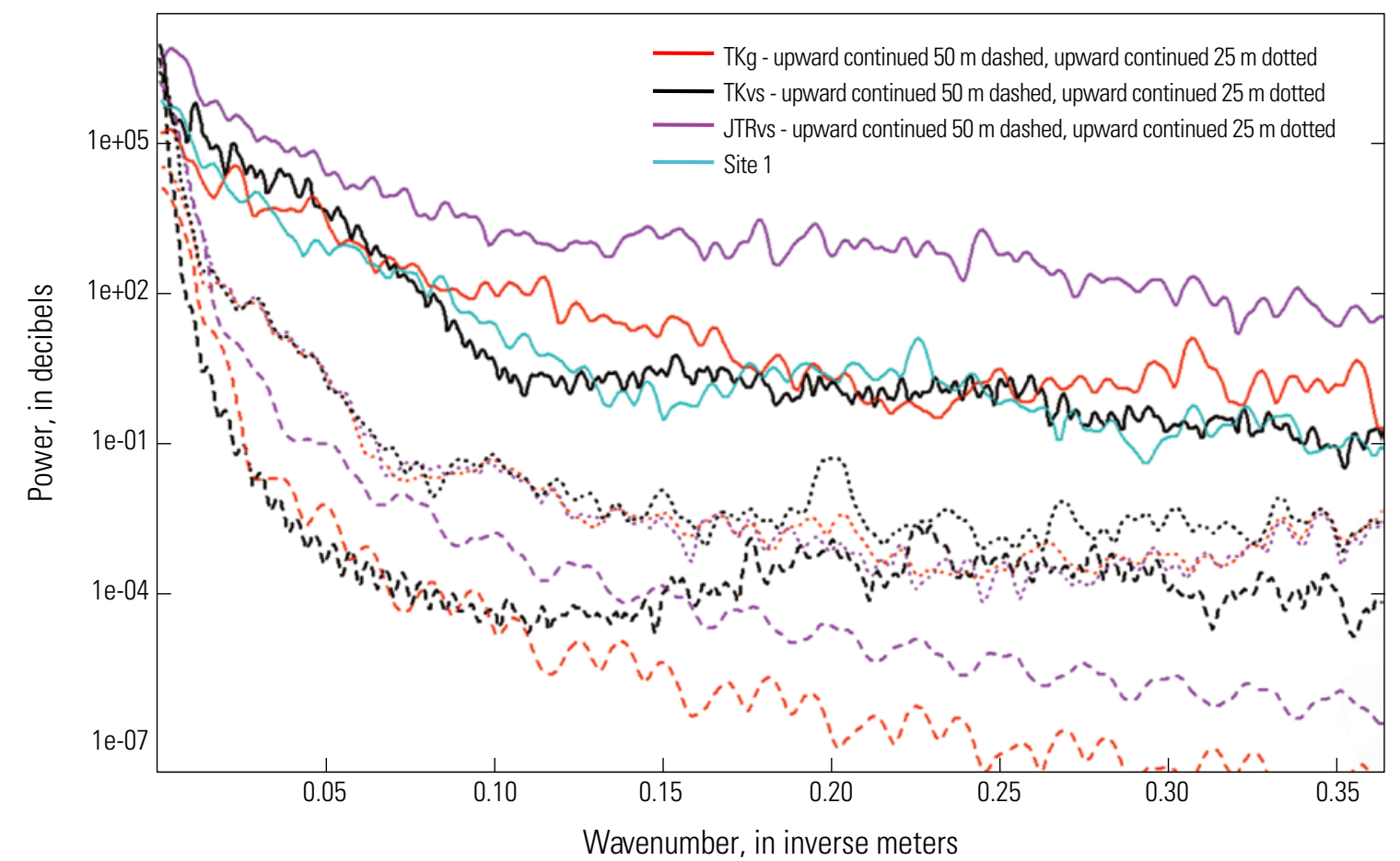


the multifractal spectrum from target site 1 is unaffected by the loss of information from upward continuation, as shown in the spectra in figure 16. The left-hand side of figure 1 is probably influenced by magnetic basin fill, and so this basin fill must be responsible for the left side of the spectrum at target site 1. Results seen in the power spectrum of target site 1 could also indicate that the power spectrum is being influenced by magnetic basin fill. Target site 1 lies near a wash that was likely to have a high concentration of Fe oxide minerals at the surface (fig. 9). Because the left-hand side of the multifractal spectrum is influenced by the basin fill here, the best way to use the multifractal spectrum to help estimate concealed lithology is to compare the location of the spectrum in as well as the shape of the top and right side of the spectrum. Here, the right side of the spectrum is most similar to the upwardcontinued spectrum of map unit JTVs, contributing to the evidence that the concealed lithology is, indeed, this map unit.

On the basis of the above analysis, the logical candidate for the concealed lithology at target site 1 is map unit JTRvs. After the initial analysis described above, the magnetic signal from deep basin fill was added to those of the upward-continued candidate lithologies and reanalyzed for target site 1 , but no significant change was observed in the descriptive statistics or spectra. Many of the descriptive statistics, as well as the power spectrum and the multifractal spectrum, indicate a large input to the magnetic signal from the basin fill at target site 1, indicating a bigger Earth's magnetic-field component due to basin fill at target site 1 than the contribution estimated from deep basin fill in the center of the basin.

\section{Structural Analysis near Target Site 1}

The heading-corrected ground-based magnetic-fieldprofile data acquired over profile 1 (fig. 10) are plotted in figure 20 , including data from target site 1 . The first $7 \mathrm{~km}$ of these data displays several regular magnetic anomalies that tend to increase in amplitude from about 2.1 to $4.5 \mathrm{~km}$ along the profile ("High-amplitude section," in fig. 20). After km 7, several very large anomalies likely indicate some major structural features.
Figure 19. Plot showing multifractal spectra of groundbased magnetic-field-profile data acquired over candidate lithologies, and upward continued 25 and $50 \mathrm{~m}$, and at target site 1 .

Figure 20. Plot showing groundbased magnetic-field-profile data acquired over basin fill along profile 1.
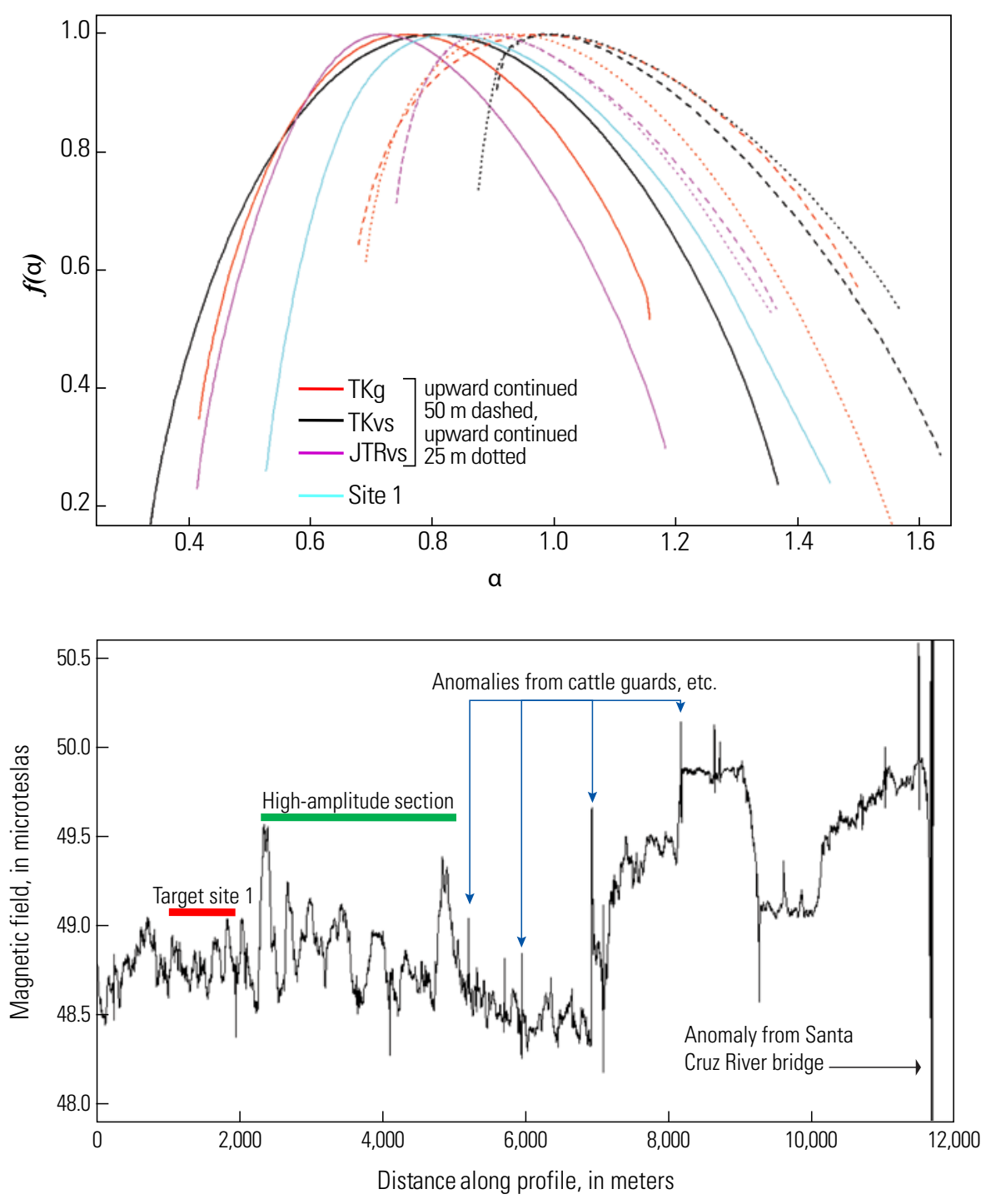
The data from profile 1 were modeled in two dimensions, using the program GM-SYS, and the results are plotted in figure 21 . The sudden change in profile direction at $7 \mathrm{~km}$ changes the shape and amplitude of anomalies in the model because the profile is based on how geologic units interact with the Earth's magnetic field in the direction of the profile. Thus, the geometry of the model is only approximate after $\mathrm{km} 7$. On the basis of the interpretation of target site 1, the concealed bedrock present there is map unit Jkvs. Although no measurements of magnetic susceptibility are available for this map unit, it is arbitrarily assigned a relatively high magnetic susceptibility of $0.008 \mathrm{cgs}$ unit, owing to its high observed mean value (fig. 11), which is not unreasonable for andesite (Clark, 1997) and could also be considered an apparent susceptibility. That is, the susceptibility used in the model is somewhat high because it includes the remanent magnetism of the rock. Andesites can have high Koenigsberger ratios, the ratio of remanent to induced magnetic intensity (Clark, 1997). Assuming the remanent magnetization is of the same polarity as the Earth's current magnetic field and that the declination and inclination of the remanent magnetism do not greatly differ from the current declination and inclination, the remanent magnetism would increase the overall magnetism of the rock. According to both Simons (1974) and Drewes and others (2002), the flow bedding in this andesite dips to the east or southeast. The magnetic anomalies present from $\mathrm{km} 1$ to $\mathrm{km}$ 7 along the profile can be modeled as higher susceptibility (0.017 cgs unit) flows or other dipping planar features in the bedrock under about $80 \mathrm{~m}$ of basin fill. Note that the area of high-amplitude magnetic anomalies ("High amplitude section," figs. 20,21) which is shown in both figures 20 and 21 can be modeled with similar flows at shallower depth (approx 30-40 m). Beyond $\mathrm{km} \mathrm{7,} \mathrm{major} \mathrm{basin} \mathrm{faults} \mathrm{and} \mathrm{a}$ very high susceptibility ( $0.025 \mathrm{cgs}$ unit) rock are needed to model the data, but note that the geometry of these features is only approximate, owing to changing profile direction. The 0.025 -cgs-unit material could be highly altered andesite or other alteration affiliated with an intrusive body. Rocks with such high magnetic susceptibilities occur in the Saddle Mountain region to the north of the basin. Basin faults lower the basin depth at $\mathrm{km} 12$ along the profile to $400 \mathrm{~m}$, which is shallower than the $600 \mathrm{~m}$ defined in the gravity-based depth model shown in figure 10. However, this model has few data points in the region, and the basin is deepening rapidly to the north at this point, and so this model is not unreasonable. To match the depth of the gravity-based model here, very high susceptibility ( $\sim 0.050 \mathrm{cgs}$ unit) material would be needed.

\section{Estimation of Concealed Lithology at Target Sites $2 a$ and $2 b$}

Target site 2 occurs in the northern part of the San Rafael Basin south of the large outcrop of map unit TKvs. In this area, map unit TKvs probably continues southward under the basin fill. This target site was split into two subsites, $2 \mathrm{a}$ and $2 b$, to test the effects of increasing depth on the estimate of concealed geology. The depth model is based on data from only a few gravity stations, and although the general geometry and overall depth of the model are good, the exact geometry of the basin margin at large scales can differ considerably from that in the model shown in figure 10, as is often the case when trying to estimate concealed lithology. Especially at target site $2 \mathrm{~b}$, the depth is only approximate because the site sits on a steep gradient with few gravity stations.
Figure 21. Figures showing profile 1, how ground-based magnetic-field-profile data provide detailed geologic model of concealed lithology and bedrock geometry.

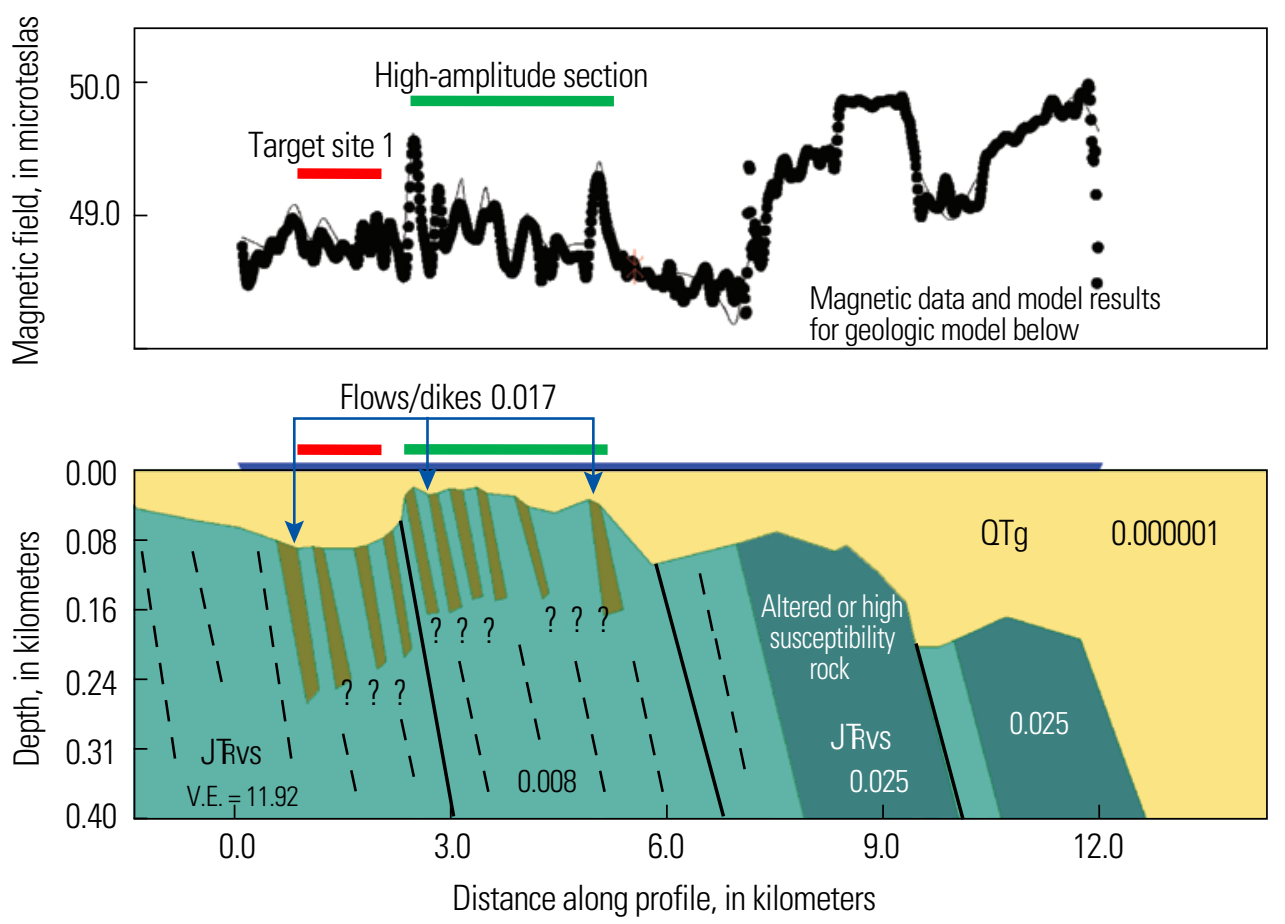


Target site $2 \mathrm{a}$ is in a narrow neck of basin fill (fig. 10) that extends to the north of the main basin. The gravity model indicates that the basin fill in this area is less than $100 \mathrm{~m}$ thick. The entire neck area is surrounded by map unit TKvs, which here is composed of trachyandesite. The acquisition area for the magnetic signature of map unit TKvs lies just to the west (fig. 10). Saddle Mountain (fig. 8), at the northwest corner of the basin neck, was mapped as unit Tg (table 1) by Drewes (1996), but Simons (1974) was somewhat more specific and mapped this feature as Cretaceous pyroxene monzonite with two included volcanic necks. Drewes' geologic map was influenced by more recent radiometric ages in the area, and he listed the age of the intrusive body as younger than map unit $\mathrm{TKg}$ (table 1). This intrusive body is extremely magnetic, and ground-based magnetic-field-profile data acquired near it have heading-corrected values of more than 52,000 nT. Groundbased magnetic-field-profile data on the outcrop of this map unit were unobtainable, owing to property access and terrain.

Target site $2 \mathrm{~b}$ is about $2 \mathrm{~km}$ to the south of target site $2 \mathrm{a}$ (fig. 10), where the bedrock depth is supposedly near $400 \mathrm{~m}$. As mentioned above, this depth estimate is based on data from only a few gravity stations (fig. 10) over a steep gradient and is likely to be incorrect. On the basis of textures visible in ground-based magnetic-field-profile data, bedrock in this area is probably not so deep and is likely more than $100 \mathrm{~m}$ but less than $150 \mathrm{~m}$ deep. Most short-wavelength $(<50 \mathrm{~m})$ textural information from bedrock disappears at depths greater than $150 \mathrm{~m}$, even for concealed lithologies with very high magnitude anomalies, such as map unit JTRvs. Three deep exploration wells were drilled in the basin in the 1970s (Arizona Department of Water Resources, 2009; red dots, fig. 10), one of which is only about $1.5 \mathrm{~km}$ southeast of target site $2 \mathrm{~b}$ and reached 2,004 feet $(611 \mathrm{~m})$ deep without penetrating bedrock. On the basis of this information, a very steep increase in bedrock depth probably occurs south of target site $2 \mathrm{~b}$. The bedrock "canyon" seen on the northwest side of the basin in figure 10 and trending northwest is probably not real because it is based on data from only two gravity stations (fig. 10) and has depth contours extending into the exposed bedrock. On the basis of the 2,004-ft-deep well and another 1,893-ft (577 m) deep well (fig. 10), which also did not penetrate bedrock, the bedrock depth gradient in the western and northern parts of the basin is steeper than that shown in the gravity-based model (fig. 10). Owing to the textures in the ground-based magneticfield-profile data, a shallow margin occurs on the north side of the basin that includes target site $2 b$.

The ground-based magnetic-field-profile data acquired at target sites $2 \mathrm{a}$ and $2 \mathrm{~b}$ are plotted in figure 22 along with the magnetic signatures of the high-amplitude candidate lithologies. Although the concealed lithology at both sites is believed to be map unit TKvs on the basis of the proximity of outcrop to the north, the means of the data at target sites $2 \mathrm{a}$ and $2 \mathrm{~b}$ are much higher than that of map unit TKvs. The magnetic signal at target site $2 \mathrm{a}$ is probably influenced by or derived from the pyroxene monzonite of Saddle Mountain that must extend at depth southward at least to this area.

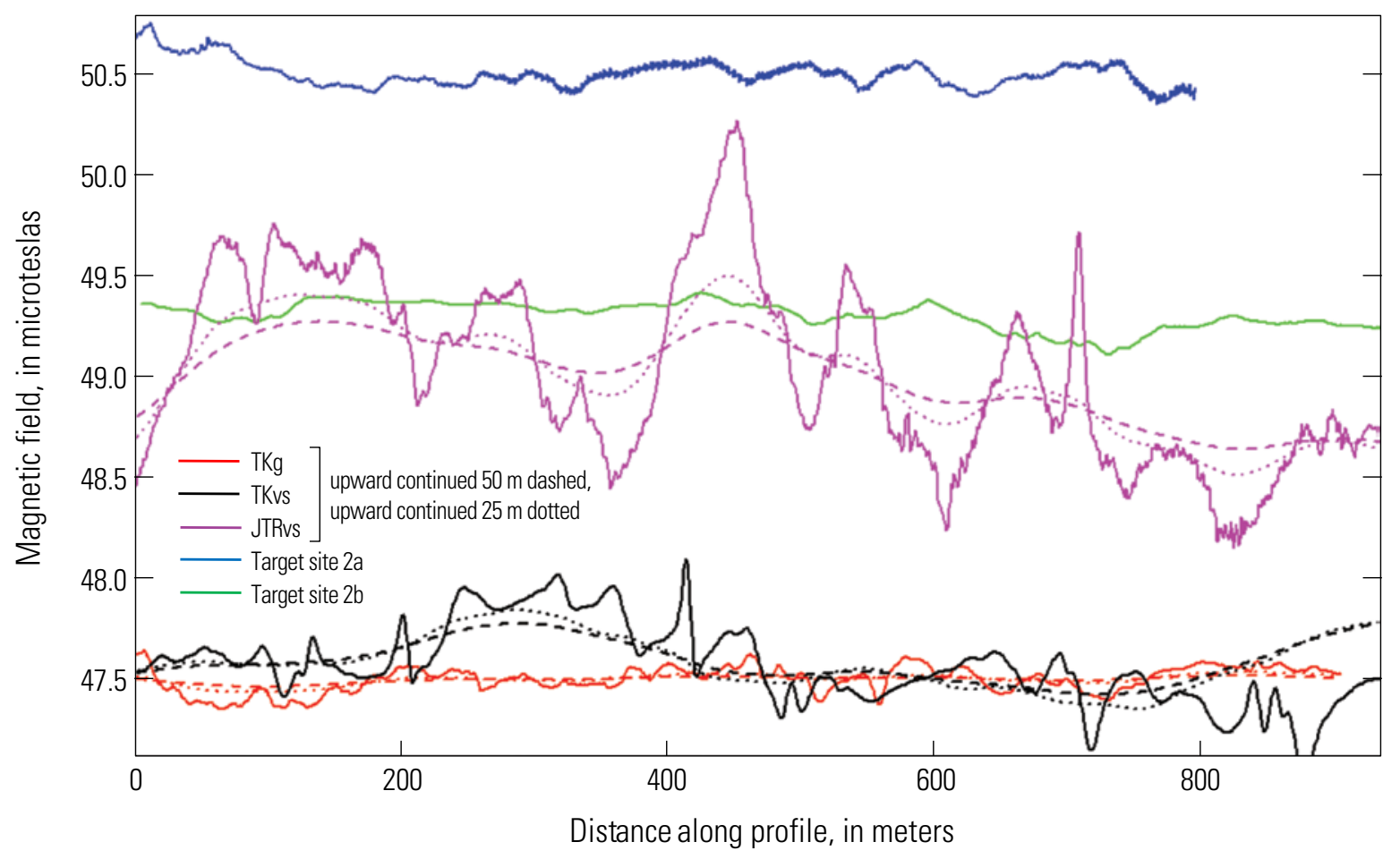

Figure 22. Plot showing ground-based magnetic-filed-profile data from target sites $2 a$ and $2 b$, plotted with magnetic signatures of three high-amplitude candidate lithologies, with upward-continued data at 25 and $50 \mathrm{~m}$. 
Target site $2 b$ is $2 \mathrm{~km}$ farther south, and although the mean is high, it is nearly identical to that of map unit JTRvs. The textures at both target site $2 \mathrm{a}$ and $2 \mathrm{~b}$ are most similar to that of map unit JTRvs, especially given that target site $2 b$ is concealed by at least $100 \mathrm{~m}$ of basin fill.

From the descriptive statistics in table 2, the mean $B$ value is what stands out most at target sites $2 \mathrm{a}$ and $2 \mathrm{~b}$. Target site $2 \mathrm{~b}$ has a mean $B$ value similar to that of map unit JRvs, only about $370 \mathrm{nT}$ higher, but target site $2 \mathrm{a}$ has a mean $B$ value of about 50,500 nT, a full 1,600 nT higher. As indicated above, this difference is likely due to the presence of the pyroxene monzonite of Saddle Mountain at depth. At both target sites 2a and $2 \mathrm{~b}$, the $p / x$ and $V / x$ values would tend to indicate that map unit JRvs is the concealed lithology, whereas the MPH value would tend to indicate map unit TKvs. Again, the MPHW, signal range of $B$, and standard deviation of $B$ are not of much help. Because the depth at target site $2 \mathrm{~b}$ is probably greater than $100 \mathrm{~m}$, map unit JRvs is the only candidate lithology that could cause the mean peak height, standard deviation, and signal range observed at target site $2 \mathrm{~b}$.

The power spectra of target sites $2 \mathrm{a}$ and $2 \mathrm{~b}$ is plotted in figure 23 along with the power spectra from the three highamplitude candidate lithologies. From wavenumbers 0.08 to 0.12 , both target sites $2 \mathrm{a}$ and $2 \mathrm{~b}$ have more power than map unit TKvs. These wavenumber represent anomaly wavelengths of 8.3 to $12.5 \mathrm{~m}$, and the power from these anomalies may be contributed by basin fill. Nonetheless, a contribution to power at anywhere near the magnitude needed is not observed in that part of the spectrum from basin fill in the central part of the basin (fig. 13). The spectrum from target site $2 \mathrm{a}$ also has more power than map unit TKg at wavenumbers near 0.17 to 0.19 , indicating that the power spectrum is probably not produced by map unit TKg.

The multifractal spectra from target sites $2 \mathrm{a}$ and $2 \mathrm{~b}$ and the high-amplitude candidate lithologies is plotted in figure 24. For both target sites $2 \mathrm{a}$ and $2 \mathrm{~b}$, there appears to be little contribution to the spectra from basin fill; that is, the left-hand sides of the spectra are missing. The top and right-hand side of the multifractal spectrum from target site $2 \mathrm{~b}$ mimics the right-hand side of the upward-continued spectrum from map unit JTRvs. The multifractal spectrum from target site 2a shows no resemblance to any upward-continued spectra. Because this spectrum lies to the left of the multifractal spectrum of exposed map unit TKvs, it cannot be derived from map unit TKvs.

On the basis of the analysis of ground-based magneticfield-profile data from target sites $2 a$ and $2 b$, the concealed lithology at target site $2 \mathrm{a}$ cannot be identified. Neither descriptive statistics, power spectra, nor multifractal spectra help uniquely identify a concealed lithology. The magnetic signal acquired at target site $2 \mathrm{a}$ is probably due to the pyroxene monzonite of Saddle Mountain. This interpretation would explain the high mean of the magnetic signal from that site, as well as the absence of any textural match to the candidate lithologies.

Target site $2 \mathrm{~b}$ has a mean, MPH, signal range, and standard deviation that most resemble those of map unit JRvs concealed by $100 \mathrm{~m}$ or more of basin fill. In addition, both the power spectrum and multifractal spectrum provide evidence that supports the conclusion that map unit JKvs underlies basin fill at this site.

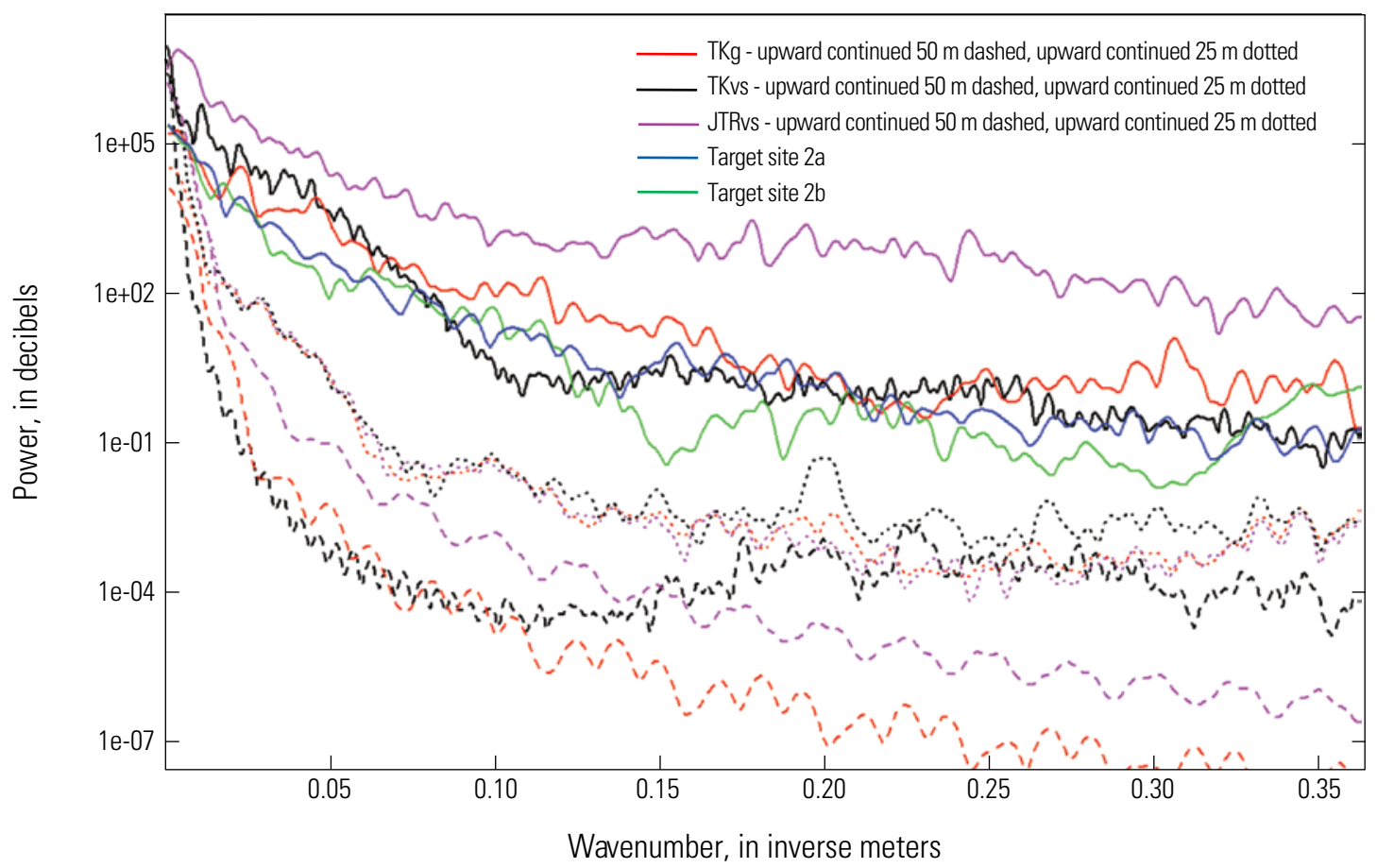

Figure 23. Plot showing power spectra for target sites $2 \mathrm{a}$ and $2 \mathrm{~b}$ and three high-amplitude candidate lithologies, (and upward continued 25 and $50 \mathrm{~m}$ ). 


\section{Modeling Bedrock Structure over a Potential Mineral-Resource Target}

The ground-based magnetic-field-profile data acquired from northeast to southwest along profile 2 (fig. 10) are plotted in figure 25. The bearing used for heading correction was $210^{\circ}$ true, the average bearing along the profile. Although some turns are evident in this profile, they all have a large radius of curvature, and the data appear to have been properly corrected. From the gravity-based depth model, the basin is shallow here, about $100 \mathrm{~m}$. Eight gravity stations were added in the vicinity of this profile to help control model depth in this area. A relatively shallow depth seems to be confirmed by the high amplitude of magnetic anomalies and by the texture visible in the ground-based magnetic-field-profile data in figure 25. One obvious feature is bounded on the northeast side by the Dove Canyon Fault. This magnetic anomaly is formed by two nearly symmetrical highs, one of which is more than 1,000 nT, separated by a central low and bounded by even-lower values of the Earth's total-intensity magnetic field to the southwest.

Porphyry copper deposits commonly appear as magnetic highs with alteration halos generally manifested as surrounding annular magnetic lows (Berger and others, 2008). The central high is commonly due to potassic alteration, which often includes magnetite. The annular low is due to destruction of magnetite within the surrounding propolytic- and phyllicalteration zones; however, magnetic susceptibility varies
Figure 24. Plot showing multifractal spectra of ground-based magnetic-field-profile data acquired over candidate lithologies, (and upward continued 25 and $50 \mathrm{~m}$ ) and from target sites $2 \mathrm{a}$ and $2 \mathrm{~b}$.
Figure 25. Plot showing headingcorrected groundbased magneticfield-profile data for profile 2 .
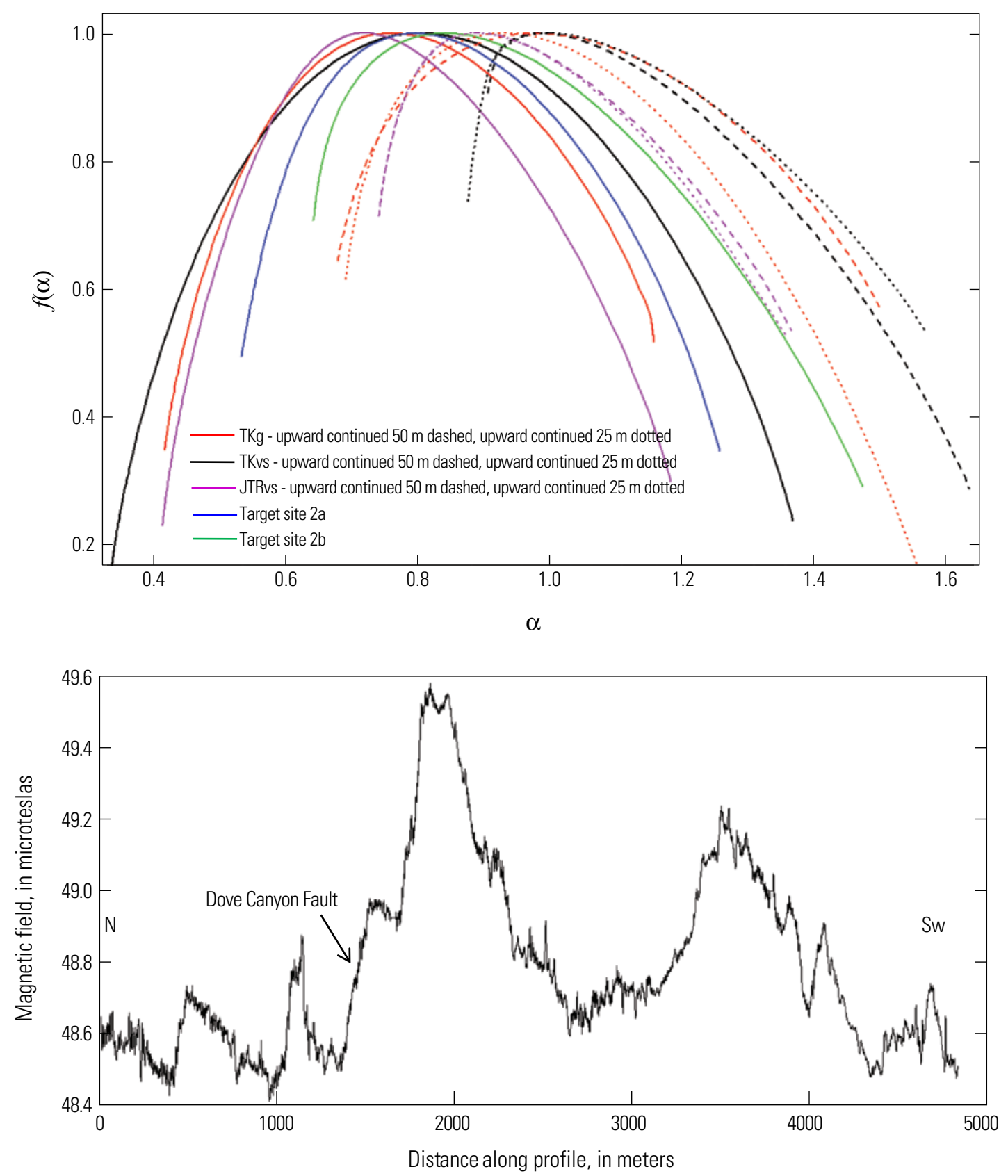
significantly throughout the altered rock in porphyry systems (Gettings, 2005). Whether owing to this variation or to the absence of a strong central potassic-alteration zone, some porphyry systems can display a central magnetic low and have been referred to as nonmagnetic porphyries (Clark and others, 1992). The nearby Sunnyside porphyry copper system, (area2, fig. 8; SP, fig. 12) has no known associated central magnetic high. The magnetic anomaly shown in figure 25 is due either to a nonmagnetic porphyry system or to a porphyry system where the potassic-alteration zone has been weathered from the top of the porphyritic stock responsible for the system, leaving only high-magnetic-susceptibility potassic alteration on its margins.

The best aeromagnetic data from the study area are shown as a decorrugated grid in figure 12. Although a slight magnetic high is visible in profile 2 (where it is intersected by the northeasterly green line whose intersection indicates the northeastern most magnetic high in fig. 25), it is by no means as prominent or distinguishing a feature as the same anomaly in the ground-based magnetometer data, owing to the location of the aeromagnetic-survey line and the altitude of the survey (nearly $300 \mathrm{~m}$ here). The survey lines near the anomaly happen to be a little more widely spaced in this area than the overall 1/3-mi spacing of the survey as a whole. The southwestern magnetic anomaly in figure 25 (800 nT in the ground-based data) is almost invisible in figure 12 (southwestern green line intersecting profile 2).

The ground-based magnetic-field-profile data from profile 2 are plotted in figure 26. In this area, map unit JRvs is composed of siliceous tuff and has much different magnetic properties than near the Patagonia Mountains. The magnetic anomaly has been modeled here as if it is caused by a porphyry copper system in which potassic alteration has been eroded from the top of the system and remains only adjacent to the intrusive stock that formed the system. The system was then buried by Cenozoic sedimentary deposits.

\section{Conclusions}

Ground-based magnetic-field-profile data acquired with a truck-mounted Cs-vapor magnetometer can complement aeromagnetic data in studies of the geometry, structure, and lithology of bedrock concealed by basin fill. Although aeromagnetic data are useful at smaller scales (tens to hundreds of kilometers), ground-based magnetic-field-profile data are most useful at scales of hundreds to thousands of meters. They provides high-resolution data of the Earth's total-intensity magnetic field acquired near the ground and at closely spaced locations, which

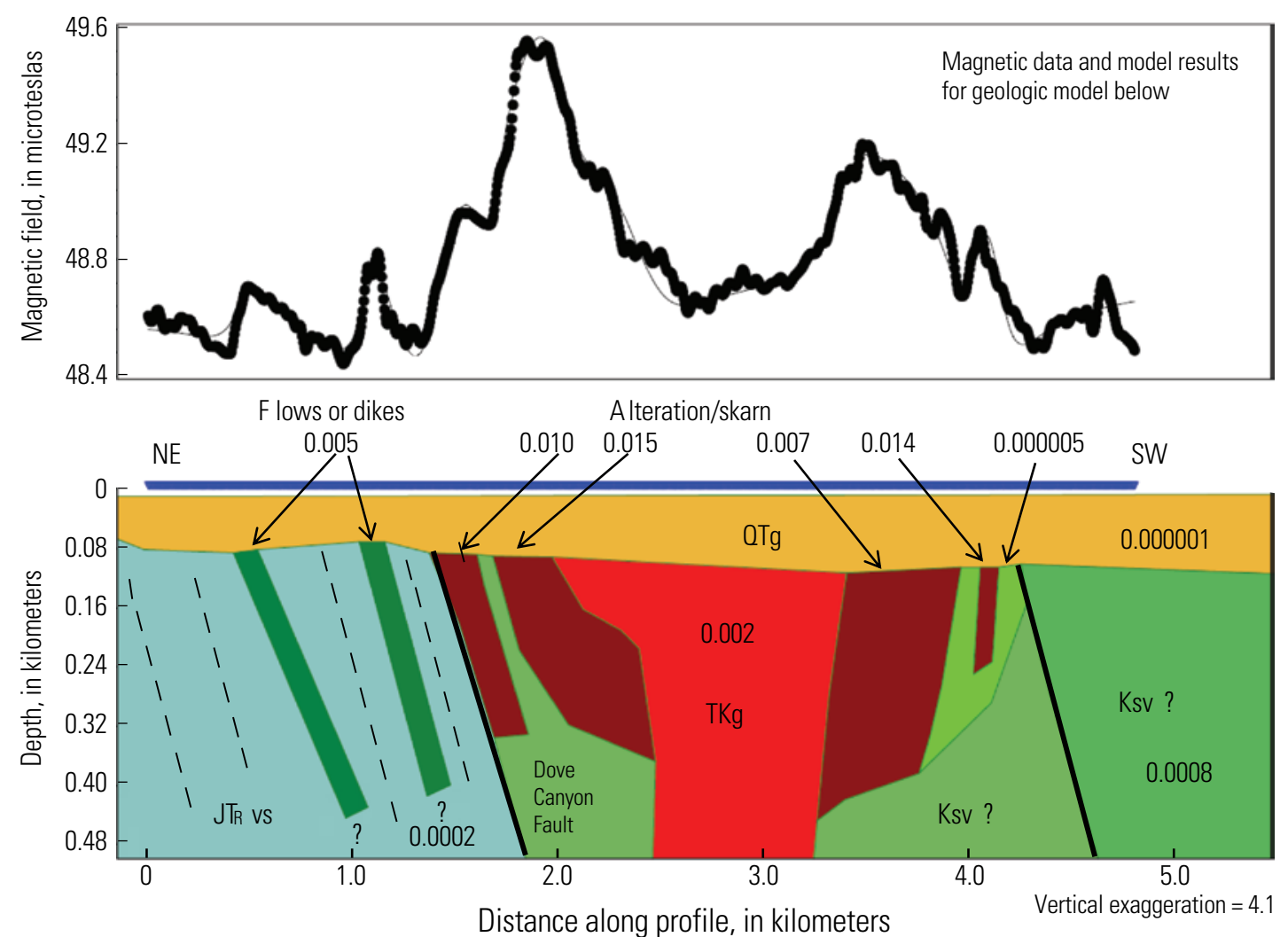

Figure 26. 
are needed for precise structural modeling and for the large-scale estimation of concealed lithology in some cases.

Estimation of concealed lithology is based on four methods: graphical analysis, descriptive statistics, and analysis of both the power spectra and multifractal spectra of the ground-based magnetic-field-profile data. Estimation is not quantitative but uses information from these four methods to remove some potential candidate lithologies from consideration and possibly to deduce a concealed lithology. Graphical analysis provides information on the mean value of the magnetic field and the ability to visually compare the textural properties of the exposed and concealed lithologies. Descriptive statistics provide quantitative evidence for characterizing the textural properties of the data that can be compared between exposed and concealed lithologies. The descriptive statistic of the mean of $B$ is important, as well as the values of MPH, $p / x$ and $V / x$. Standard deviation of $B$, range of $B$, and MPHW value are not particularly effective at discriminating concealed lithology, probably owing to the influence of the magnetic signal from basin fill.

The power spectra of ground-based magnetic-fieldprofile data provide boundary conditions that can also be used to eliminate potential concealed lithologies from consideration. In general, the power spectrum of the magnetic signal from an upward-continued candidate lithology must always display less power at all wavenumbers than the power spectrum of the magnetic signal from a target site where that candidate lithology is buried. Otherwise, that candidate lithology can be eliminated from consideration as a concealed lithology. The power spectrum from the deep basin fill in the San Rafael Basin has a hundredth to a thousandth of the power at all wavenumbers of the power spectra of any of the candidate lithologies. Therefore, adding the magnetic signal from basin fill acquired in the central part of the basin to the magnetic signal from upward-continued candidate lithologies did not affect any comparisons of power spectra. However, at the target sites that are near the basin-fill/bedrock contact, more of a contribution to the total magnetic signal from basin fill certainly occurs than if the composition of the basin fill was identical to that in the central part of the basin.

I propose here that the multifractal spectrum of ground-based magnetic-field-profile data can be used for estimating concealed lithology by matching the right side of the spectrum (for $\alpha>f(\alpha)=1$ )for the upward-continued (by estimated depth of burial) magnetic signal from the estimated concealed lithology and the magnetic signal from the target site. Although more research needed, this method does seem to work for target sites in the San Raphael Basin and has a logical basis. At target site 1, a well-constrained area with a concealed lithology with a very high magnetic amplitude, the method does help determine the concealed lithology. At target site $2 \mathrm{~b}$, which is deeper and where the depth is less constrained, the method also provides information as to what lithology might be concealed. At target site $2 \mathrm{a}$, the multifractal spectrum does not point to any candidate lithology being concealed but does help determine what lithology is not concealed.

Ground-based magnetic-field-profile data are extremely important in understanding the geometry and structure of basin margins at scales of hundreds to thousands of meters. Such data allow for precise models that help in depth determination, basin structural evaluation, and target assessment that are impossible to construct by using aeromagnetic data. Given the benefits of estimating concealed lithology and of precision modeling of basinmargin geometry and structure, acquisition and analysis of ground-based magnetic-field-profile data becomes an extremely important component in the understanding of concealed mineral resources in the Basin and Range, as well as in many other regions.

\section{References}

Arizona Department of Water Resources, 2009, Water resource data well registry database: https://gisweb.azwater. gov/waterresourcedata/, accessed August 2009.

Berger, B.R., Ayuso, R.A., Wynn, J.C., and Seal, R.R., 2008, Preliminary model of porphyry copper deposits: U.S. Geological Survey Open-File Report 2008-1321, 55 p.

Berkowitz, B., and Hadad, A., 1997, Fractal and multifractal measures of natural and synthetic fracture networks: Journal of Geophysical Research, v. 102, no. 36, p. 12205-12218.

Bloomfield, P., 2000, Fourier analysis of time series; an introduction ( $2 \mathrm{~d}$ ed.), New York, Wiley, $288 \mathrm{pp}$.

Bultman, M.W., 1999, Geometry, structure, and concealed lithology of the San Rafael Basin, southeastern Arizona: U.S. Geological Survey Open-File Report 99-399 [http:// geopubs.wr.usgs.gov/open-file/of99-399].

Bultman, M.W., and Drewes, H.D., 1996, Mineral resources, ore deposit models, and resource potential of Coronado National Forest; locatable minerals, chap. $\mathrm{G}$ of du Bray, E.A., ed., geology of Coronado National Forest, southeastern Arizona and southwestern New Mexico: U.S. Geological Survey Bulletin 2083, p. 144-168.

Bultman, M.W., and Gettings, M.E., 1994, New techniques of geophysical data analysis; an investigation of the geometry, structure, and bedrock lithology of the San Rafael Basin, Arizona, USGS Research on Mineral Resources-1994, Part A-Program Abstracts., http://pubs.er.usgs.gov/djvu/CIR/ circ_1103_a.djvu. 
Clark, D.A., 1997, Magnetic petrophysics and magnetic petrology; aids to geological interpretation of magnetic surveys: Journal of Australian Geology and Geophysics, v. 17 , no. 2, p. 83-103.

Clark, D.A., French, D.H., Lackie, M.A., and Schmidt, P.W., 1992, Magnetic petrology; application of integrated rock magnetic and petrologic techniques to geologic interpretation of magnetics surveys: Exploration Geophysics, v. 23, p. 65-68.

Dolan, S., Bean, C., and Riollet, B., 1998, The broad-band fractal nature of heterogeneity in the upper crust from petrophysical logs: Geophysical Journal International, v. 132, p. 489-507.

Drewes, H.D., Fields, R.A., Hirschberg, D.M., and Bolm, K.S., 2002, Spatial digital database for the tectonic map of southeast Arizona: U. S. Geological Survey Geologic Investigations Series I-1109. http://pubs.usgs.gov/imap/ i1109/.

Drewes, H.D., 1996, Geology of Coronado National Forest, chap. B, of du Bray, E.A., ed., geology of Coronado National Forest, southeastern Arizona and southwestern New Mexico, U.S. Geological Survey Bulletin 2083, p. 17-41.

Falconer, K.J., 1990, Fractal geometry; mathematical foundations and applications: New York, Wiley, 288 p.

Feder, J., 1988, Fractals: New York, Plenum Press, 283 p.

Geometrics Inc., 1996, G-823A Airborne cesium magnetometer operation manual: Sunnyvale, Calif., 39 p.

Gettings, M.E., 1995, Cantor set models of magnetic sources: XXI General Assembly of the International union of Geodesy and Geophysics, Abstracts Week B, Boulder, Colorado, July 2-12, 1995.

Gettings, M.E., 1999, Using textural measures of aeromagnetic data to infer lithology [abs.]: International Union of Geodesy and Geophysics XXII General Assembly Abstracts, Birmingham, England, Week A, p. A390.

Gettings, M.E., 2002, An interpretation of the 1996 aeromagnetic data for the Santa Cruz basin, Tumacacori Mountains, Santa Rita Mountains, and Patagonia Mountains, south-central Arizona, U.S. Geological Survey Open-File Report 02-099, http://pubs.usgs.gov/of/2002/ of02-099/.

Gettings, M.E., 2004, A dataset of magnetic susceptibility, metallization, and alteration for samples from the Stinkingwater Mining District, Absaroka Mountains, Wyoming, U.S. Geological Survey Open-File Report 04-1253, http://pubs.usgs.gov/of/2004/1253/.
Gettings, M.E., 2005, Multifractal magnetic susceptibility distribution models of hydrothermally altered rocks in the Needle Creek Igneous Center of the Absaroka Mountains, 281 Wyoming: Nonlinear Processes in Geophysics, v. 12, p. $587-601$.

Gettings, M.E., 2006, a multifractal model of magnetic susceptibility in hydrothermally altered rocks: Eos (American Geophysical Union Transactions), v.87, no. 52, Fall Meeting, abstract NG43B-1155.

Gettings, M.E., 2008, A quantitative method to identify lithology beneath cover: Eos (American Geophysical Union Transactions), v. 89, no. 53, abstract GP43B-0799.

Gettings, M.E., in press, Model studies of magnetic susceptibility in hydrothermally altered rocks. Journal of Geophysical Research.

Gettings, M.E. and Bultman, M.W., 1997, Detailed ground magnetic anomaly profiles used in delineation of Southwest U.S basin structure, Scientific Assembly of International Association of Geomagnetism and Aeronomy (IAGA), 8th Uppsala, Sweden, 1997.

Hagstrum, J.T., 1994, Remagnetization of Jurassic volcanic rocks in the Santa Rita and Patagonia Mountains, Arizona; implications for North American apparent polar wander: Journal of Geophysical Research, v. 99, no. B8, p. 103-113.

Heathcote, R.L., 1983, The arid lands; their use and abuse: London, Longman, 323 p.

Hildenbrand, T.G., Berger, B., Jachens, R.C., and Ludington, S., 2000, Regional crustal structures and their relationship to the distribution of ore deposits in the western United States, based on magnetic and gravity data: Economic Geology, v. 95, p. 1583-1603.

Lévy Véhel, J, and Legrand, P., 2004, Signal and image processing with FracLab: FRACTAL04, Complexity and Fractals in Nature, International Multidisciplinary Conference, 8th, 2004, Vancouver, B.C., Canada, 2004, Proceedings, p. 321-322.

Lovejoy, S., Pecknold, S., and Schertzer, D., 2001, Stratified multifractal magnetization and surface geomagnetic fields-I. Spectral analysis and modeling: Geophysical Journal International, v. 145, p. 112-126.

Maus, S., and Dimri, V., 1996, Depth estimation from the scaling power spectrum of potential fields: Geophysical Journal International, v. 124, p. 113-120.

Pecknold, S., Lovejoy, S., and Schertzer, D., 2001, Stratified multifractal magnetization and surface geomagnetic fields-II, Multifractal analysis and simulations: Geophysical Journal International, v. 145, p. 127-144. 
Phillips, J.D., 2002, Processing and interpretation of aeromagnetic data for the Santa Cruz Basin-Patagonia Mountains area, south-central Arizona: U.S. Geological Survey Open-File Report 02-98, http:/geopubs.wr.usgs. gov/open-file/of02-98/.

Pilkington, M., and Todoeschuck, J.P., 1993, Fractal magnetization of the continental crust: Geophysical Research Letters, v. 20, no. 7, pp. 627-630.

Pierce, H.W, 1985, Geologic framework of Arizona, in Hendricks, D.M., Arizona soils: Tucson, University of Arizona Press, p. 15-32.

Simons, F.S., 1974, Geologic map and sections of the Nogales and Lochiel quadrangles, Santa Cruz County, Arizona: U.S. Geological Survey Miscellaneous Investigations Series Map I-762, scale 1:48,000.

U.S. Geological Survey, 2009, Mineral Resources Data System: http://tin.er.usgs.gov/mrds/, accessed May 2009. 
Menlo Park Publishing Service Center, California

Manuscript approved for publication, February 26, 2013

Edited by George Havach

Design and layout by Jeanne S. DiLeo 
总 